AEC Research and Development Report

\title{
THE NUCLEAR TEST GAUGE
}

- by

T. F. Parkinson, M. H. Goosey, W. M. Heston, and $H$. J. Hollberg

Savannah River Laboratory

June 1956

classiflation Cancelled or Charged

ro uncharof fef

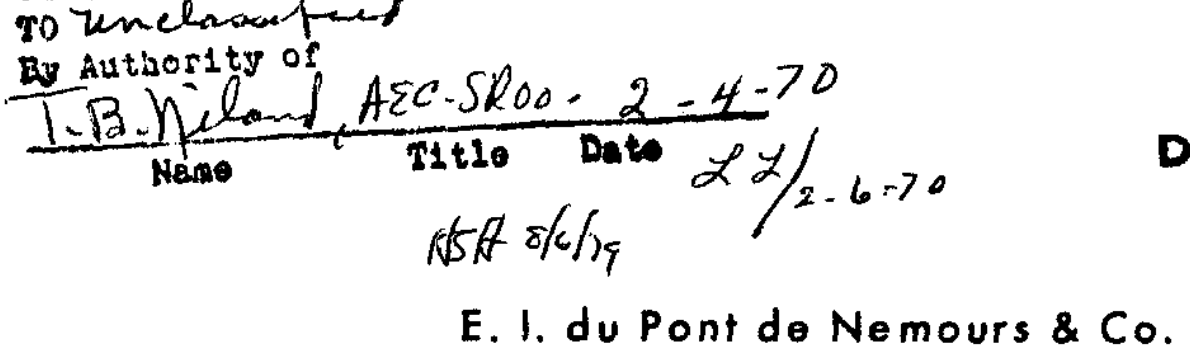

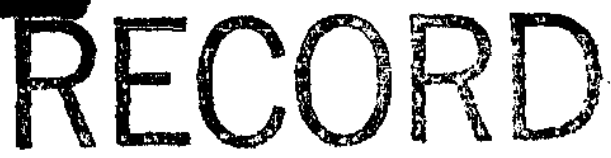

Explosives Department - Atomic Energy Division

Technical Division - Savannah River Laboratory

NOT FIELEASE

FROM FILE 
This report was prepared as an account of Government sponsored work. Neither the United States, nor the Commission, nor any person acting on behalf of the Commission:

A. Makes any warranty or representation, express or implied, with respect to the accuracy, completeness, or usefulness of the information contained in this report, or that the use of any information, apparatus, method, or process disclosed in this report may not infringe privately owned rights; or

B. Assumes any liabilities with respect to the use of, or for damages resulting from the use of any information, apparatus, method, or process alsclosed in this report.

As used in the above, "person acting on behalf of the Commission" includes any employee or contractor of the Commission to the extent that such employee or contractor prepares, handles or distributes, or provides access to, any information pursuant to his employment or contract with the commission.

Printed in USA. Price $\$ 0.50$

Avallable from the U. S. Atomic Energy Comission Technical Information Service Extension

P. 0. Box 1001, Oak Ridge, Tennessee

Please direct to the same address inquiries covering the procurement of other clas ifled AEC reports. 


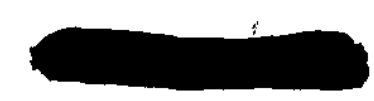

$D P-147$

REACTORS - RESEARCH AND TESTING

\section{THE NUCLEAR TEST GAUGE}

by

Thomas F. Parkinson, Malcolm H. Goosey, William M. Heston, and Herbert J. Hollberg

Savannah River Laboratory

Work done by

I. M. Arnett

H. R. Fike

H. J. Hollberg

R. C. Robinson
D. Baker

M. H. Goosey

T. F. Parkinson

o. A. Towler

June 1956

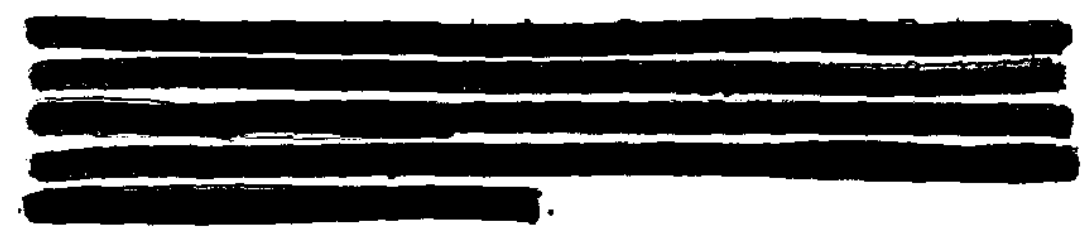

E. I. du Pont de Nemours \& Co.

Explosives Department - Atomic Energy Division

Technical Division - Savannah Rlver Laboratory

Printed for

The United States Atomic Energy Commission Contract $\mathrm{AT}(07-2)-1$ 


\section{ABSTRACT}

The "Nuclear Test Gauge", a slightly subcritical assembly for quality control of reactor components, was designed, constructed, and placed in operation. Calibration experiments demonstrated that the sensitivity of the unit is adequate, and that the speed of testing is increased by a factor of ten over that of a critical test pile.

External Distribution according to M-3679 (18th Ed.) 


\section{INTERNAL DISTRIBUTION}

No. of Copies

(5) AEC, SROO

(1) R. M. Evans -

B. H. Mackey

(I) J. E. Cole -

M. H. Smith -

J. B. Tinker

(I) H. Worthington

1) D. F. Babcock

(1) J. C. Woodhouse

(1) M. S. Bloomsburg

(I) "W" File

(1) S. I. Winde

(I) J.A. Monier

I W. P. Overbeck

1) T. C. Evans

1) R. D. MicCrosky

(1) W. M. Eaton

1) F. J. Kaufman

I I. S. HaII

(1) K. W. Millett

(1) P. D. Deans -

R. P. Coon

(1) T. R. Beck

I J.C.McMilian

(I) PRD File

(I) M. H. Wahl -

C. W. J. Wende

(I) W. M. Heston

(I) J.W. Croach

(1) G. Dessauer

I P. H. Permar

I J. I. CrandalI

(I) J.N.Wilson -

L. Cathey

(I) D. Baker, Jr。

(I) T. F. Parkinson

I) $\mathrm{M} \cdot \mathrm{H} \cdot$ Goosey

(I) H. J. Hollberg

(15) TIS File

(1) TIS File Record Copy
Aiken, S. C.

Wilmington AED
11
11
$n$
11
n)

Engineering Department

Savannah R1ver Plant

n

11

11

11

if

$n$

II

11

II

II

Savannah River Laboratory

"1

11

11 
INTRODUCTION

SUMMARY

DISCUSSION

Description of the Assembly 6

General Arrangement 6

The NTG Tank 6

The Lattice 6

The Source 7

The Moderator System 7

Shielding 8

Instrumentation 8

The Safety System 9

Calibration Experiments 11

Operational Characteristics 11

Initial Loading 12

Statistical Weight in the Sample Hole 12

Noise Level in the Ion Chambers 12

Flux Distribution in the NTG 13

Testing Experiments 13

Slugs of Enriched Uranium-Aluminum Alloy 13

Slugs of Natural Uranium 14

Lithium-Aluminum Slugs 15

Tubes of Enriched Uranium-Aluminum Alloy 15

Uranium Plates 16

Results 17

Nuclear Hazards $\quad 17$

APPENDIX

Design and Characteristics of the Ion Chambers 19

The Differential Electrometer 19

Control Circuit 20

Noise Level in the Ionization Current 20

Hypothetical Excursion in the NTG with $k=1.002$

BIBLIOGRAPHY 23 


\section{IIST OF FIGURES}

Figure

Page

1 Drawing of the Assembly

2 Photograph of the Assembly

3 Tank, Top Vlew

4 Tank and Dump Valve Assembly

5 Tank Details

6 Moderator System

7 Shielding and Source Location

8 Typical Section of Recorder Chart

9 Safety system

10 Support Frame for Safety Sheets

I1 Block Diagram of the Scram System

12 Loading Curve

13 Lattice Configuration for $k=0.990$

14 Lattice Configuration for Testing Slugs of

Enriched Uran1um-Aluminum Alloy

15 Axial Flux Distribution in the NTG

16 Radial Flux Distribution in the NTG

17 Effect of Sample Length on $k$

18 Calibration for Slugs of Enriched Uranium-Aluminum Alloy Containing Four to Seven Per Cent by weight Uranium

19 Correlation of NTG and Test Plle Data for Slugs of Enriched Uranium-Aluminum Alloy Containing Four to Seven Per Cent by Weight Uranlum

20 Correlation of NTG and Test Plie Data for Slugs of Enriched Uranium-Aluminum Alloy - Slugs Nominally

Five Per Cent by weight Uranium

21 Effect of D1splacing Sample from the Center of the Core

22 Lattice Configuration for Testing Natural Uranium Slugs and Lithium-Aluminum Slugs

2-3- Caltbration for Natúräl Uranium Slugs

24 Calibration for Slugs of Lithium-Aluminum Alloy

25 Correlation of NTG and Test Pile Data for Slugs of Lithium-Aluminum Alloy

26 Assembly for Testing Tubular Fuel Elements

27 Lattice Configuration for Testing Tubes of Enriched Uranium-Aluminum Alloy

28 Calibration for Tubes of Enriched Uranium-Aluminum Alloy

29 Effect of Enriched Tubes on the Effective Mult1plication Constant

30 Axial Traverses of Tubular Elements

31 Assembly for Testing Plate Fuel Elements

32 Lattice Configuration for Testing Plate Fuel Elements

33 Neutron-Sensitive Ion Chamber

34 Cross Section of Ion Chamber

35 Schematic Diagram of the Differential Electrometer

36 Control Circuit 


\section{THE NUCLEAR TEST GAUGE}

\section{INTRODUCTION}

It is desirable to test pile components before they are charged into a reactor that operates at high specific power. one of these tests is the measurement of the "specific reactivity" of the component. This test is usually performed by measuring the effect that the component has on the kinetic behavior of a chain-reacting "test pile". This danger coefficient measurement, however, is time consuming and requires a large initial investment in equipment.

The testing time can be reduced by operating the pile at a reactivity sufficiently below criticality to minimize the effects of the delayed neutrons. In a subcritical condition the testing for reactivity consists of the observation of changes in the neutron population or in the "multiplication".

In view of the advantages of speed, safety, and simplicity that might be derived from this method, experiments were made to determine whether the method provided enough sensitivity to compete with an existing test pile.(I) These experiments $(2)$ demonstrated that a subcritical assembly of enriched uranium not only is superior to a test pile of natural uranium by a factor of ten in speed of testing, but also is equivalent to the test pile in sensitivity. In view of the success of those exploratory experiments, the decision was made to design and construct a production model of a subcritical test pile. The device is called the "Nuclear Test Gauge", or NTG.

The present report describes the mechanical features, the instrumentation, and the safety features of the NTG. The results of loading and calibration experiments are also discussed.

\section{SUMMARY}

A "Nuclear Test Gauge" was designed, constructed, and placed in operation. It is a slightly subcritical assembly that is used for quality control of reactor components. It consists of a strong neutron source and sufficient fissionable material and moderator to yield a multiplication of approximately 100. Calibration experiments demonstrated that the sensitivity of the NTG is adequate, and that approximately one minute is required to make a measurement compared with the ten minutes required for a danger coefficient measurement in a chain-reacting test pile. Other advantages of the NTG over a chain-reacting pile are lower capital investment and lower operating costs, the ability to resolve inhomogeneities in long pile components, the ease with which the NTG can be adapted to test difierent types of samples, and the greater inherent safety of a subcritical assembly.

The NTG is equipped with a system of safety sheets that are inserted within 0.3 second after the initiation of a scram signal. 
The safety sheets control sufficient reactivity to shut the NTG down promptly in case of any concelvable supercritical excursion caused by an error in loading.

\section{DISCUSSION}

\section{DESCRIPTION OF THE ASSEMBLY}

General Arrangement

The Nuclear Test Gauge was designed to accommodate a variety of reactor components. As shown in Figures 1 and 2 , the NTG tank has horizontal fuel tubes, and a central sample tube which 1s part of a removable plug. The safety devices include two safety sheets which are mounted above the tank and can be dropped into the fuel lattice, and a dump valve which drains the moderator into a dump tank located below the NTG tank. Concrete shielding surrounds the tank on four sides. Access through the shielding to either face of the fuel lattice is provided through openings that are covered by loading doors and removable shielding tanks which are filled with water. Both safety sheets are inserted automatically into the lattice and the moderator is dumped automatically by the scram circuit if any attempt is made to open the loading doors during operation. The light-water moderator is circulated continuously during operation from the dump tank through an ion exchange resin and filter into the NTG tank. The level of the moderator in the tank is controlled by an overflow tube which carries water to the dump tank. The neutron detectors consist of six ion chambers, lined with B-IO, which are located inside the NTG tank.

\section{The NTG Tank}

Details of the NTG tank are iliustrated in Figures 3 and 4. The tank is formed from $2 S^{-}$aluminum plate that is one-quarter inch thick. The tank is 38-7/8 inches long, 38-1/4 inches wide, and $44-1 / 4$ inches high.

The Lattice

The lattice is composed of 120 thin-walled tubes of $2 \mathrm{~S}$ aluminum, each 38-7/8 inches long. Each tube has an O.D. of 1.090 inches and an I.D. of 1.020 inches. The tubes are arranged in a hexagonal array with a center-to-center spacing of 1.687 inches, as shown in Figure 5 .

In critical experiments made at Oak Ridge National Laboratory (3), the spacing of 1.687 inches was found to be the optimum spacing for minimum critical mass. With this spacing, any accidental deformation of the core produces a decrease in the reactivity of the assembly. A change of 0.1 inch in the lattice spacing reduces $k$ by one per cent. It will be noted in Figure 5 that the lattice spacing was modified along two vertical planes to accommodate the two safety sheets. 
The fuel occupies the central two feet of each fuel tube. Rods of polyethylene are inserted at each end of the fuel tubes. This arrangement provides an effectively infinite reflector of water around the core because the moderating properties of the plastic are very similar to those of light water. The fuel is enriched uraniumaluminum alloy in the form of cylinders, one inch in diameter and 12 inches long. The extrapolated critical mass of the NTG is $4.09 \mathrm{kilo-}$ grams of U-235 for the lattice shown in Figure 14; the mass of fuel in the NTG at a multiplication of 100 is $4.00 \mathrm{kilograms}$ of $\mathrm{U}-235$. The loading varies, depending on what material is being tested. This small mass gives the critical NTG such a large advantage in sensitivity over a conventional critical test pile(l) that the subcritical NTG becomes sensitive enough for nuclear testing, whereas a subcritical pile of natural uranium would not be sensitive enough.

The seven central tubes are situated in a hexagonal polyethylene plug that extends the length of the tank (Figure 3 ). This plug can be removed and, by means of suitable adapters, specimens of different shapes and sizes up to an O.D. of 3.5 inches can be accommodated.

The Source

A polonium-beryliium source was used to supply neutrons to the assembly. During the experiments described in this report the source strength varied from $6.6 \times 10^{7}$ to $1.9 \times 10^{7}$ neutrons per second. The location of the source in the lattice is shown in Figure 13.

\section{The Moderator System}

The moderator of the NTG is deionized light water. The water is stored in the dump tank whenever the NTG is shut down. It is pumped from the dump tank through a column that contains a mixture of cation and anion exchange resins. The deionized light water then passes through a ten-micron filter, which is in the line to prevent dispersion of resin throughout the system. The water then enters the NTG tank. The water level in the tank is controlled by the height of an overflow tube. This tube returns the overflow to the dump tank, and the cycle is repeated. The system is designed to circulate the moderator at the rate of three $\mathrm{gpm}$. The arrangement of the equipment and of the piping is shown in Figure 6. A moderator level indicator is located on the front face of the NTG.

The dump valve shown in Figure 4 is of sufficient size to drain the water to the midplane of the lattice in five seconds.

The size of the dump tank is sufficient to store all of the light water in the system. Iight water can be added to the system through the line shown in Figure 6 to make up for losses. 


\section{Shlelding}

The shielding design can be séen in Figure I. A concrete wall two feet thick and nine feet high surrounds the entire assembly except for openings on the sides and on the top. Additional shielding for thermal neutrons is provided by a cadmium Iiner, 1/32 inch thick, which is placed on the inner face of the concrete. Both the NTG tank and the dump tank can be removed through the top of the shielding structure should this become necessary.

openings through two opposite faces of the concrete shield provide access to the fuel tube lattice. During operation of the NTG each of these openings is shielded as shown in figure 1 by a waterfllled tank which is 24 inches thick, and by a lead-filled loading door which is $2-3 / 4$ inches thick. A seven-inch hole through the loading door is shielded by a lead cover shown in Figure 7 . This cover aligns the source and flxes its position in the fuel lattice by means of a locking clamp. A second opening in the cover accommodates the sample carrier tube which extends through the shielding tank and engages the center tube of the hexagonal plug. A similar cover on the rear face of the NTG has only one opening which permits discharge of the test samples.

Loading and unloading of the fuel in the NTG requires the removal of both the loading doors and the water-filled shield tanks. Test samples, however, can be loaded and unloaded without removing the shielding.

\section{Instrumentation}

The neutron detectors are six ion chambers lined with $\mathrm{B}-10$. These chambers are suspended inside the fuel tank. The ion currents from two of these chambers are amplified on two Beckman micromicroammeters, which in turn actuate the scram system. These Beckman micromicroammeters can be seen in Figure 2. The remaining four ion chambers are connected in paraliel and feed the differential electrometer. Except for the ion chambers and the differential electrometer(4), commercially available instruments were used. This differential electrometer incorporates a source of bucking current together with a scale expansion feature which permits changes in the ion current of the order of 0.1 per cent to be measured. The output from the differential electrometer is registered on a Brown recorder, which is also shown in Figure 2. A typical section of recorder chart is.shown in Figure 8. It illustrates the response time, the sensitivity, and the noise level. The lower part of the trace shows the flux at equilibrium for an acceptable sample. Then a sample of lower concentration was inserted and the flux fell off sharply, coming close to equilibrium in one minute. The new sample contains about $1.5 \mathrm{gm}$ of U-235 less than the standard.

The details of construction and circuit diagrams for the ion chambers and the differential electrometer are discussed in the Appendix. 
During loading, a LiI (Sn) scintillation counter is provided to monitor the neutron flux several feet away from the core.

\section{The Safety System}

Although the NTG is not meant to go critical, many safety features are included that are common to chain-reacting assemblies. Two large safety sheets are suspended above the fuel tank. The safety sheets are of $1 / 8$-inch thick boral. The boral is clad with aluminum and welded into aluminum frames. The reactivity worth of the safety sheets, $\Delta k / k$, was measured to be approximately minus 30 per cent. When the sheets are inserted into the fuel lattice, they divide the lattice into three sections. The sheets are suspended by electromagnets which are attached to cables carrying manually operated counterweights outside the shielding. Interruption of the electrical current to the electromagnets will release the safety sheets at any time, regardless of their position. Approximately 0.3 second is required for the sheets to fall freely into the lattice from the fullout position. Moistened cellulose sponges on the tank top snub the fall of the sheets. This system is shown in Figure 9. The safety sheet support frame, which is shown in Figure 10, has "Micarta" guides that extend into the lattice and act as runways for the safety sheets.

The light-water moderator can be removed very quickly from the tank by means of an air-operated dump valve, which will drain the water to the midplane of the core in five seconds. The quick opening valve is shown in Figure 4. It consists of an air cylinder and gasketed closure disc. The closure disc is forced by air pressure against an eight-inch opening in the bottom of the NTG tank. When a scram signal occurs, a solenoid-actuated valve reverses the direction of air pressure on the piston, quickly forcing the closure disc downward. Air for operation of the dump valve is supplied from a receiver tank which is located on top of the NTG tank. A small compressor outside the shielding maintains the pressure in the receiver tank.

The scram system of the NTG, which is composed of two independent circuits, will cause the safety sheets to fall and the dump valve to open simultaneously if an unexpected increase occurs in neutron level, or if the loading doors in the NTG tank are raised during operation. A block diagram of the scram circults is shown in Figure 11. The scram system consists of two Iinear Beckman micromicroammeters, the control panel, and the associated power supplies. A scram can be initiated in either of the two channels which are independent up to the control relays. The micromicroammeters derive their input signals from two of the neutron-sensitive ion chambers. These chambers are located on opposite sides of the lattice in the moderator to afford protection even if the flux distribution is asymmetric. A Weston "Sensitrol" meter-relay is connected in series with the meter in the micromicroammeter, and is adjusted such that the contacts on the meter-relay pull in at about 95 per cent of ful. scale. When these contacts pull in they cause a Western Electric relay, No. $275 B$, to drop out. If the power fails this relay also drops out, which gives a "fail safe" feature to this part of the 
circuit. The contacts on each of the western Electric relays are connected in series with the scram line in the control circuit proper. Each of these relays can be bypassed by means of switches on the control panel. The scram circuit is so arranged, however, that if both of the independent scram lines are bypassed simultaneously a scram will occur. Bypassing is necessary to preclude spurious scrams when the range of the Beckman micromicroammeters is changed. The bypass switches, as well as the main power switches, are key operated to prevent unauthorized use. Red lights on the control panel, which is shown in Figure 2, indicate when a scram circuit is bypassed. A green Iight on the control panel indicates when the safety sheets are "cocked".

Another safety feature is a system of interlock switches. Two of these microswitches trigger the scram circuit if either of the loading doors is raised. Another microswitch performs the same function if the tank is lifted from its support. A fourth microswitch controls the power to the dump valve solenoid switch and prevents closing the dump valve unless the safety sheets are raised.

Detailed explanations of the action of the circuit following a scram and of the circuit diagram are given in the Appendix.

Further protection against nuclear accidents is afforded by the design of the sample carrier. If the lattice of the NTG is arranged to test neutron-absorbing specimens such as target pleces, 1t is important that no fissionable specimen be inserted in the sample tube. The sample carrier is slotted to accept only one size of sample. If an attempt is made to insert a different size sample, the error is immediately obvious.

Another safety precaution is the slow rate at which the water is raised in the tank. The time required to fill the tank is approximately 20 minutes. This is slow enough to allow effective operation of the scram devices if raising the water brings the NTG to -criticality.

These include:

Operational procedures incorporate other safety features.

1. All changes in the fuel configuration are made with the water drained from the tank, with the neutron source inserted in the lattice, with the safety sheets cocked, and with two independent scram circuits in operation.

2. Suitable lattice configurations are used for testing each material that is available. The highest $k$ attained during routine operation is 0.990 with enriched uranium slugs in the sample holder.

3. The water 1 s drained from the tank at the end of each day.

4. Proper operation of the two scram circuits is confirmed each day before the water is pumped in. 
5. The safety sheets are cocked before the water is pumped in.

6. The neutron source is always inserted in the lattice before the water is pumped in.

7. Only the type of material being tested is allowed in the vicinity of the NTG.

\section{CALIBRATION EXPERIMENTS}

\section{Operational Characteristics}

Equations that describe the kinetics and the sensitivity of a subcritical pile have been discussed in DP-48(2). The timedependent behavior of $\mathrm{N}$, the number of neutrons produced per second, when small changes in the fuel loading are made, can be represented by:

$$
N(t, k)=S M \pm \Delta N e^{-t / \ell M}
$$

$S$ is the number of neutrons per second emitted by the source; $M$ is the multiplication, $\frac{1}{1-k} ; k$ is the effective multiplication constant; $\Delta N$ is the change in neutron production resulting from a small change in $\mathrm{k}$; $t$ is the time; and $\ell$ is the effective neutron lifetime.

The change in the equilibrium value of $\mathrm{N}$ resulting from a change, $\Delta m$, in the amount of fuel is found by differentiating the time-independent part of $\mathrm{N}$ in Equation 1 with respect to $\mathrm{m}$. To carry out this differentiation one must know the behavior of $k$ as a function of $\mathrm{m}$. Experiments with the NTG showed that, for values of $k$ above 0.95 , this relationship was linear:

$$
\frac{\Delta k}{\Delta m}=\frac{a}{m_{0}}
$$

where $\alpha$, the shape of the "loading curve", depended on the statistical weight of the loading position, and where $m_{0}$ is the critical mass of the assembly. With this expression for $\frac{\Delta k}{\Delta m}$, the relation between changes in neutron production and loading becomes:

$$
\Delta N=\frac{\alpha S M^{2}}{m_{0}} \Delta m
$$

If the change, $\Delta \mathrm{m}$, is small, $\mathrm{N}$ is a linear function of $\mathrm{m}$. For significant changes in the loading, the change in multiplication M must be taken into account when the recorder chart is calibrated in terms of the fuel content of the test specimens. 


\section{Initial Loading}

The Ion chamber currents and the count rates were measured for a multiplication of one (1.e., with the source inserted and the water raised) before the fuel was loaded into the lattice. These values served as a reference to compute the multiplications of subsequent loadings. Since these experiments extended over a period of several months, the reference values had to be corrected for the decay of the source.

Before fuel was added, the source was inserted, the water was drained, and the safety sheets were cocked. After each addition of fuel, the water was raised slowly and the multiplication was measured. The water was then dumped to get ready for the next loading: step. Smaller increments of fuel were added in subsequent steps, as criticality was approached. The average of the inverse multiplication is plotted in Figure 12 as a function of the mass of U-235 in the core. The lattice configuration that produced a multiplication of $100(k=0.99)$ is shown in Figure 13. The tubes that did not accommodate fuel or the source were filled with polyethylene rods.

\section{Statistical Weight in the Sample Hole}

The sensitivity of the NTG depends on the statistical weight of the central channel as shown in Equations 2 and 3 . The statistical weight could be increased by removing some of the fuel. from the innermost ring of tubes and then adding to some of the peripheral positions to compensate for the resulting reduction in multiplication. The sensitivity, $\Delta \mathrm{N} / \Delta \mathrm{m}$, of the lattice shown in Figure 13 was determined by measuring the change in the differential electrometer reading when two samples of known but different concentrations were alternately positioned in the sample hole. The lattice was altered by removing the fuel from the innermost ring of tubes, and the sensitivity was measured again. The lattice configuration shown in Figure 14 was selected as the optimum lattice for testing slugs of enriched uranium-aluminum alloy. The value of $\alpha$ (See Equation 2) for this lattice was 2.8 .

Noise Level in the Ion Chambers

For a given multiplication, source strength and critical mass, the limit in sensitivity of the NTG depends on the noise level in the neutron-detecting system. Accordingly, several precautions were taken to minimize noise: (1) the instruments derived their power from a "Stabiline" electronic voltage regulator; (2) ground connections were made in such a way as to avoid ground loops; and (3) leads from the ion chambers were carefully shielded. The calculations in the Appendix indicate that the remaining noise is of the order to be expected from the statistical fluctuations in the ion current.

To achieve a high signal-to-noise ratio, and hence, a high sensitivity, the largest possible fraction of neutrons leaking from the core must be detected. The primary detecting system for most of 
the experiments consisted of four boron-lined ion chambers connected in parallel. For the measurements reported for slugs of enriched uranium-aluminum alloy and slugs of natural uranium, however, only two chambers were avallable. Had all chambers been of equal efficiency for detecting neutrons and placed in regions of equal fiux, the sensitivity of the NTG should have doubled when the number of chambers was doubled. The measured ratio of sensitivities was 1.7 .

For operating convenience, a $0.1-\mu f$ condenser was placed between the common signal lead from the ion chambers and ground. The condenser served to smooth out ion chamber fluctuations without seriously lengthening the response time.

Flux Distribution in the NTG

Radial and axial flux traverses were made with indium foils which had a thickness of $100 \mathrm{mg} / \mathrm{cm}^{2}$, for the lattice shown in Figure 14. Each foll was counted on two end-window beta counters. The saturated activities corrected for decay, counter dead time, and foil weight, are shown in Figures 15 and 16 as functions of position in the NTG lattice.

The axial traverse was made in lattlce position (07,35) (See Figure 14). For the radial traverse, one group of foils was placed between fuel pieces, while another group of foils was placed in the moderator. For a given radius, the latter foils were more active than the former.

The axial flux extended over a distance of about 38 inches. Any portion of a sample outside this interval had no effect on the neutron population. The reactivity worths of samples of different lengths were estimated as proportional to the square of the flux integrated over the extent of the sample. Figure 17 is a plot of relative worth versus sample length. The contribution to the reactivity of a 24-inch sample of enriched uranium-aluminum alloy was compared experimentally with that of a 12.5-inch sample. The ratio of the changes in reactivity produced by these was found to be 1.5 , in fair agreement with the calculated value of 1.4 .

TESTING EXPERIMENTS

Slugs of Enriched Uranium-Aluminum Alloy

The NTG was calibrated with special slugs of enriched uranium-aluminum alloy, each 12.49 inches long and 1.005 inches in diameter, whose nominal composition ranged from four to seven per cent uranium. The composition was later measured by chemical analysis. The calibration curve is shown in Figure 18. These same sIugs were also run in the Savannah River Test Pile, which is a large graphite-moderated assembly similar to the Hanford Test Pile(1). The correlation between the NTG and the rest Pile results is shown in Figure 19. 
A second plot, which correlates data that cover a smaller range of concentrations, is shown in Figure 20. These tests were made on slugs that were intended to contain identical amounts of uranium. The limits of acceptable concentrations are indicated. The error shown corresponds to the noise in the output of the differential electrometer. The minimum detectable cross section was calculated to be plus or minus $0.07 \mathrm{~cm}^{2}$ from the known difference in macroscopic absorption cross section of two samples that could be resolved by the NTG.

The precision with which a 12-inch sample, which is approximately one-third the length of the core, had to be positioned was determined by observing the change in the differential electrometer reading as the sample was displaced from the center of the core. The results are shown in Figure 21. Displacement of the sample plus or minus 0.25 inch from the center position did not change the ion current.

All of the preceding measurements were made by inserting single 12-inch samples in the central channel. As each sample was removed, the flux decreased sufficiently to drive the differential electrometer off scale. When the next sample was inserted, about two minutes were required for the flux to reach equilibrium. This waiting time was reduced to approximately one minute by maintaining a continuous column of samples in the center. Since the combined worths of two pieces adjacent to the central piece is approximately 50 per cent of that of the central piece, it is desirable that they be standards of known concentration. With the lattice shown in Figure 14, the continuous column of slugs produced a multiplication of $104(\mathrm{k}=0.990)$, while a single sample piece in the center produced a multiplication of $52(k=0.981)$. A typlcal section of recorder chart is shown in Figure 8 which illustrates the response time, the sensitivity, and the noise level.

Slugs of Natural Uranium-

A lattice that was found sultable for testing slugs of natural uranium is shown in Figure 22. With a full charge of natural uranium slugs in the central channel, the multiplication of the assembly was $101(k=0.990)$. With the center empty, the multiplication was $54(k=0.98)$.

Each slug was eight inches long; they were tested in groups of three. Standard slugs were placed at each end of a test group of three slugs to provide a continuous column of pieces for the central channel. Some of the slugs were fabricated from reclaimed uranium. The U-235 content of these slugs was in the range 0.708 to 0.718 per cent by welght.

The calibration of the NTG for natural uranium was made by means of standards that had been assayed in the Test Pile. Measurements were made on slugs that were produced from elght ingots. Each sample used in the Test Pile measurements contained ten slugs, while several groups of three slugs from each ingot were tested in the NTG. 
A plot of NTG differential electrometer readings against isotopic content as determined in the Test P1le is shown in Figure 23. The indicated error represents the standard deviation of several measurements on the same ingot. The fact that this deviation is larger than that encountered with the slugs of enriched uranium-aluminum alioy may be due to variations, either dimensional or isotopic, within slugs from a single ingot.

The standard deviation was equivalent to plus or minus 0.0004 per cent by weight U-235 for the sample of three slugs, or plus or minus 0.001 per cent by weight U-235 for a single eight-inch slug.

\section{Lithium-Aluminum Slugs}

The NTG was calibrated for lithium-aluminum alloy slugs by using the same loading that was used to calibrate natural uranium slugs (Figure 22). With the central hole empty, the multiplication was $54(k=0.981)$; when a sample of lithium-aluminum alloy was inserted, the multiplication decreased to $25(k=0.960)$. The sample was approximately ten inches long, 0.8 inch in diameter, and contained about 3.5 per cent lithium by weight.

A group of samples that ranged in concentration from 3.3 to 3.7 per cent by weight was procured for purposes of calibration. A flame photometer was used to analyze a small section from each sample for lithium content. These samples were also measured in the Test Pile. The calibration curve for these pieces is shown in Figure 24; the correlation between NTG and rest Pile measurements is given in Figure 25. Since the latter curve shows a better correlation, it appears that the samples that were submitted for analyses were not representative of the entire sample.

The standard deviations of these measurements represent uncertainties in the lithium content of plus or minus 0.07 per cent by weight. This precision can be improved by modifying the lattice to give higher multiplications. However, this precision is adequate for routine testing, and the lower multiplication affords greater safety.

Tubes of Enriched Uranium-Aluminum Alloy

To insert tubular samples into the NTG, the central hexagonal plug had to be replaced. A photograph of the hexagonal plug assembly for tubular elements is shown in Figure 26. A lattice that was found suitable for testing tubular elements of enriched uraniumaluminum alloy is shown in Figure 27.

The NTG was calibrated by means of a group of tubes whose composition, according to the amount of materials used in their fabrication, varied from 14 to 16 per cent total uranium by weight. Chemical analyses were made on small samples taken from the ingots from which the tubes were extruded. The variation of the NTG differential electrometer readings is plotted in Figure 28 against both the 
chemical analyses and the materlal balances. Since the multiplication changed from 55 to 95 for these measurements, the Iinear relation found in the earlier calibrations no longer held. However, according to Equation 2, a plot of the effective multiplication constant, $k$, against concentration is expected to be linear. This is shown in Figure 29, which suggests that the material balance data are more nearly representative than the chemical analyses. This interpretation was substantiated subsequently when buckling measurements were made with the tubes in a critical assembly. The chemical analyses were made on small portions of each ingot; the importance of a nondestructive nuclear test, which indicates the U-235 content averaged over a much larger volume, is obvious. Subsequent work has accounted for most of the discrepancies in the chemical analyses.

From calibrations repeated on the same tubes over periods of several weeks, the standard deviation of the mean was estimated to be plus or minus 0.03 per cent by weight $U-235$.

The tubular fuel elements that were tested in the NTG were five feet long. To ascertain the axial uniformity of the tubes, they were "scanned" in the NTG by inserting them stepwise in increments of one foot. The NTG responds either to nonuniformity in the uranium concentration or to nonuniformity in the wall thickness of the tube. A concentration change of 0.1 per cent by weight is equivalent to a change in wall thickness of 0.0005 inch. The results of traverses on three tubes are shown in Figure 30; from top to bottom, these curves represent cases of good, typical, and poor uniformity. The differential electrometer deflection corresponding to a concentration change of 0.1 per cent by weight U-235 or to a change in wall thickness of 0.0005 inch is indicated on the figure.

\section{Uranium Plates}

Another type of fuel element tested was a plate of either natural or sightly enriched uranium. The enriched plates contained 1.5 per cent by weight U-235. The hexagonal adapter for this type element is shown in Figure 31. A suitable lattice for this test is shown in Figure 32. The values of the multiplication and the effective multiplication constant, $k$, that were obtained are summarized below:

NTG RESULTS FOR PLATES

$\begin{array}{lcc}\text { Type of Sample } & \text { Multiplication } & \frac{k}{0.974} \\ \text { None } & 38 & 0.976 \\ \text { Natural plate, bare } & 93 & 0.989 \\ \text { Enriched plate, bare } & 92 & \end{array}$

From the difference in the effective multiplication constants for the natural and the slightly enriched plates, it is estimated that the minimum detectabie concentration change is 0.002 per cent by weight $\mathrm{U}-235$. 
RESUITS

The values of multiplication and of $k$ for the various

lattices, with and without samples in the central hole, are summarized below:

\section{MULTIPLICATIONS AND REACTIVITIES}

Type of Sample

Enriched U-AI AIIoy

Slug

Natural Uं Slug

Enriched U-AI Alloy

Tube

Li-AI Alloy Slug

Enriched U Plate

Natural U Plate

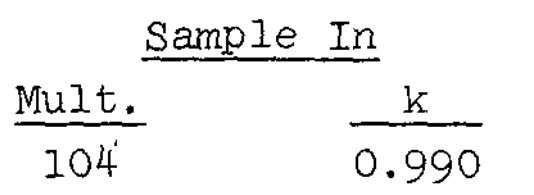

101

95

25

92

43

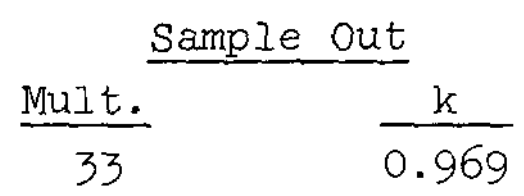

54

0.981

15

0.934

54

0.981

38

0.974

38

0.974

The precision of the Nuclear Test Gauge for measuring small changes in the concentration of samples depended on the geometry of the lattice and of the adapter and also on the strength of the neutron source at the time the measurements were made. Typical data are given in the table:

\section{PRECISION OF THE NTG}

Sample Nominal

Length, Composition,

Type of Sample

Enriched U-AI

Alloy Slug

Natural U SIug

Enriched U-AI

Alloy Tube

II-AI Alloy Slug

Enriched U Plate

Natural U Plate $\frac{\text { in. }}{12}$

$\frac{w / 0}{5.00 \mathrm{U}-235}$

8

38

10

38

38

NTG
Precision,
$\pm / 0$

Source Strength, $\mathrm{n} / \mathrm{sec}$

$3.1 \times 10^{7}$

\section{NUCLEAR HAZARDS}

The possible consequences of inserting the wrong type of sample into the various lattices that were chosen are summarized in the following table. The highest possible value of the effective multiplication constant is quoted for each particular mistake. For 
example, if the lattice were arranged to test natural urantum slugs $(k=0.990)$ and if a charge of enriched uranium-aluminum alloy slugs were inserted in the sample channel, the effective multiplication constant would increase to I.002. The substitution of any of the other test slugs, such as thorium or lithium-aluminum slugs, would decrease the effective multiplication constant to below its initial value of 0.990 .

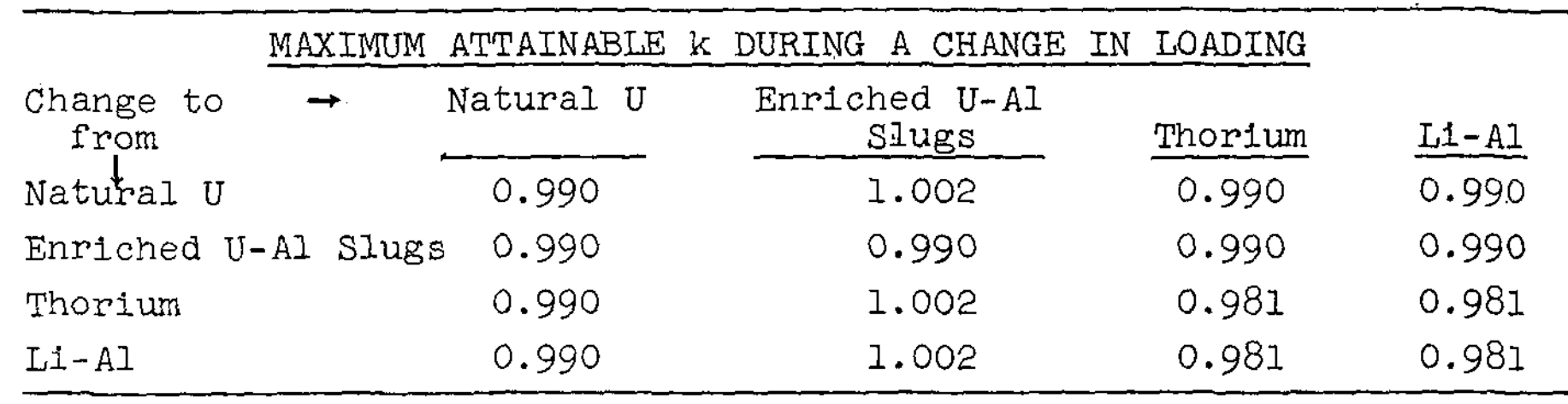

No cases were included in this table that involve tubular or plate fuel elements, since it is physically impossible to interchange these with other samples without araining the water, removing the shielding doors, and changing the adapters.

The consequences of an uncontrolled excursion with $\mathrm{k}=1.002$ are discussed in detall in the Append1x. It is assumed that the safety sheets and the moderator aump valve fail. The power excursion would proceed for approximately five minutes at which time the fuel would begin to melt. The resultant change in lattice spacing would shut down the reactor.

The radiation levels adjacent to the NTG shield are monitored during operation. In areas where personnel are required for operation, the dose rates are below six mrem per hour. When tubes of enriched uranium-aluminum alloy are tested, a fast neutron dose rate of about $20^{-}$mrem per hour is encountered immediately adjacent to the shielding doors.

Since sample slugs are inserted in the neutron flux for only a minute, they are not strongly activated and can be handled with gloves immediately following their discharge from the NTG. When longer elements, such as plates or tubes are scanned, they are $1 x-$ radiated for longer periods and the resulting activity must be allowed to decay before the elements are handled. However, by discharging the exposed element into a rack, another sample can be tested while the preceding one is cooling. In this way, delays in testing are avoided.

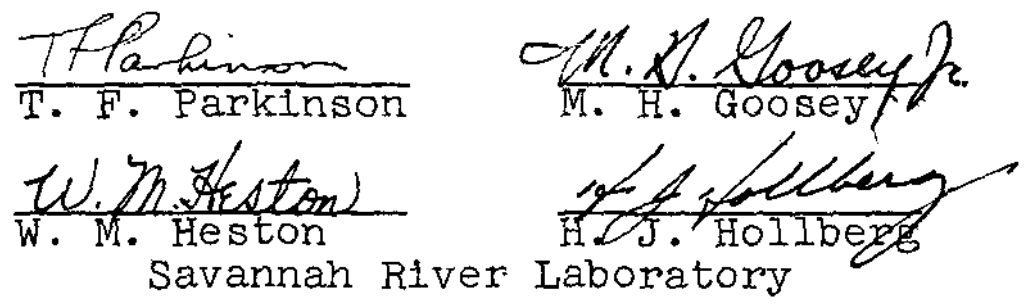




\section{APPENDIX}

\section{DESIGN AND CHARACTERISTICS OF THE ION CHAMBERS}

Neutron-sensitive ion chambers of suitable size and sensitivity were not commercially available. A chamber shown in Figure 33 was designed at the Laboratory. The sensitive volume consists of the two annular spaces formed by the three inner, coaxial, aluminum tubes. A fourth aluminum tube forms the outer case of the chamber and provides rigid mechanical support for the "Teflon" insulators. The neutron-sensitive coating materlal was fully enriched B-10 suspended in mineral oil. The tubes were first degreased in "Triclene" and then the B-10 was painted on the surfaces shown in Figure 34 with a camel-hair brush. The tubes were then baked in a nitrogen atmosphere at $300^{\circ} \mathrm{C}$ and at atmospheric pressure for two hours. The tubes were rotated continuously at approximately $30 \mathrm{rpm}$ while in the oven to obtain a uniform coating. The tubes were allowed to cool for two hours in the nitrogen atmosphere before they were removed. Two such coatings per surface were required to obtain a thickness of $0.54 \mathrm{mg} / \mathrm{cm}^{2}$. Filling arrangements were made by drilling a $1 / 4-i n c h$ hole in the plug and soft-soldering a copper tube into the hole. Electrical connections to the aluminum tubes were made by attaching clips, which were taken from female Jones plugs, over the edges of the tubes. These clips protruded through 3/16-inch holes drilled in the insulators. Two "Kovar" seals were soft-soldered into holes in the chamber cap to provide gas-tight connections to the outside of the chamber. The chambers were evacuated and then filled with argon to atmospheric pressure, evacuated, and refilled. The chambers were then sealed by pinching the copper filling tube and soldering over the end.

The chambers were placed near a neutron source and their saturation voltages were obtained. All the chambers saturated between 200 and 300 volts. Since the differential electrometer provides a. regulated $\mathrm{B}+$ supply of 300 volts, the chambers in the NTG were operated from this supply.

The linearity of the chambers was obtained by comparison of their current outputs with that from a large wide-spectrum chamber manufactured by the General Electric Company. All the chambers were linear over a current range of three decades. The sensitivity of the chambers was estimated to be on the order of $10^{-13}$ ampere per nv.

THE DIFFERENTIAL ELECTROMETER

A schematic diagram of the differential electrometer is shown in Figure 35. The bucking circuit consists of a negative voltage supply that contains two voltage-reference tubes and a tenturn "Helipot". The voltage that appears across this "Helipot" is used to buck out the voltage drop in the input resistors of the electrometer. The stability of the No. 5651 voltage reference tube is 0.1 volt. This amounts to a maximum instability, due to drift in the bucking voltage, of 0.15 per cent full scale. Drift tests on the electrometer with no input signal showed a stability of plus or minus 0.1 per cent full scale over a period of 24 hours. 
The operation of the control system will be described by consideration of the events that follow the initiation of a scram. Figure 36 is a diagram of the control circuit. Assume that the control relay circult has been broken, either by the "BeckmanSensitrol" combination, the master scram switch, or the interlock switches on the loading doors:

1. Relay No. 3 opens, interrupting the flow of current to the electromagnets that hold the boron-aluminum safety sheets out of the lattice against the force of gravity.

2. Relay No. 2 opens, interrupting the flow of current to the transformer that supplies the solenoid actuator on the dump valve.

3. Relay No. I drops out as $1 t$ is connected across the transformer mentioned in (2) above.

Relays 1, 2, and 3 are self-locking, 1.e., one of the normally open contacts is connected in series with the coil. This means that if the current in the relay coil is broken the relay will fall open and stay open, regardless of the behavior of the control signal, until the normally open contact is bridged long enough by other means for the relay to pull in again. This feature insures that a scram will go to completion even if the control signal is returned to normal. The "reset" switch performs the function of bridging the normally open contacts on Relays No. 2 and No. 3 . This switch is spring loaded to return to the open position when the toggle is released. The reset function for Relay No. I is performed by a microswitch that is mounted on the safety sheet support such that it is closed only when the safety sheet is in the "up" position. The second normally open contact on Relay No. I Is connected in -series. with the coil on Relay-No" 2. "This method of connection prevents the dump valve from being closed unless the safety sheets are in the "up" position. One set of contacts on the microswitch are used to light a green light on the control panel to indicate when the safety sheets are "cocked". The master scram button is located in the center of the control panel. The contacts on this switch are also in series with the scram line so that manual operation of the scram clrcult is possible.

NOISE LEVEL IN THE IONIZATION CURRENT

With a multiplication of 100 and a source strength of $3 \times 10^{7} \mathrm{n} / \mathrm{sec}$, the current from two chambers in parallel was about $2 \times 10^{-8}$ ampere. The statistical fluctuation to be expected is (5)

$$
\frac{\Delta 1}{1}=\sqrt{\frac{M e}{1 \tau}}
$$

where $M$ is the average number of Ion pairs produced by each neutron absorbed in B-10, e is the charge of the electron in coulombs, 1 is 
the ion current in amperes and $\tau$ is the resolving time of the detection system. The resolving time depends on the input time constant, on the time required to collect the electrons in the chamber, and on the frequency response of the amplifier.

The energy released in the $B-10(n, \alpha)$ in-7 reaction is approximately $2.5 \mathrm{Mev}$, and the energy required per ion pair in argon is approximately $25 \mathrm{ev}$. Thus $\mathrm{M} \cong 10^{5}$ ion pairs.

The response time of the system is governed principally by the response time of the recorder. It was on the order of 0.1 second. When the values are substituted in Equation (A-1), a relative noise level, $\frac{\Delta i}{1}$, of 0.3 per cent is obtained, which is approximately the observed value.

HYPOTHETICAL EXCURSION IN THE NTG WITH $k=1.002$

The following assumptions were made:

1. The effective multiplication constant increases from 0.99 to 1.002 instantaneously at time $t_{0}$

2. Both safety sheets fail to fall and the dump valve does not open.

3. No heat is transferred from the fuel to the moderator.

4. No deformation of the fuel occurs until the melting temperature is reached.

The third assumption is made on the basis that the O.D. of the fuel slugs is 1.005 inches and the I.D. of the supporting tube is 1.020 inches. The resulting alr gap tends to insulate the fuel. As the slug heats and expands, this gap decreases but does not completely close before the melting temperature is reached.

The constants used in this calculation are given below:

$\bar{\phi}$ (average flux in core at $\mathrm{k}=0.99$ ) $10^{6} \mathrm{n} / \mathrm{cm}^{2}-\mathrm{sec}$

$\sigma_{f}$ (fission cross section of $U-235$ ) $580 \mathrm{~b}$

$\sigma_{a}$ (absorption cross section of U-235) $687 \mathrm{~b}$

$\mathrm{V}$ (volume of core)

$8.3 \times 10^{4} \mathrm{~cm}^{3}$

$\Sigma_{a}^{e f f}$ (effective macroscopic absorption)

$0.0749 \mathrm{~cm}^{-1}$

$C_{p}(A I)$ (specific heat of $A I$ )

$0.214 \mathrm{cal} / \mathrm{gm}^{\circ}{ }^{\circ} \mathrm{C}$

E (energy absorbed in AI per fission)

$175 \mathrm{mev}=6.69 \times 10^{-12} \mathrm{gm-cal}$

$\Delta \theta$ (temperature rise in aluminum)

$640^{\circ} \mathrm{C}$ 
$T$ (period of reactor with $k=1.002$ ) $20.5 \mathrm{sec}$

$f$ (thermal utilization) 0.764

The initial fission rate at $k=0.99$ is given by $\phi \Sigma_{a}^{e f f} f V \sigma_{f} / \sigma_{a}$, which is $4.0 \times 10^{9}$ fissions per second. The neutron flux, at any time $t$, is proportional to $e^{t / T}$. If the heat produced is equated to the heat absorbed in the aluminum, the equation is

$$
C_{p} M \Delta \theta=E \bar{\phi} \Sigma_{a}^{e f f} f^{\prime} V \frac{\sigma_{f}}{\sigma_{a}} \int_{t_{0}}^{t_{I}} e^{t / T_{d t}}
$$

where $t_{I}$ is the time at which the temperature rise, $\Delta \theta$, is obtained. Then,

Therefore,

$$
e^{t_{I} / T}=1+\frac{C_{p} M \Delta \theta}{E \phi \Sigma_{0}^{e f f} f V \frac{\sigma_{f}}{\sigma_{a}} T}=1.80 \times 10^{7}
$$

and

$$
\frac{t_{1}}{T}=16.7
$$

Under the assumptions made, it takes 342 seconds for the fuel slugs to reach the melting point of aluminum, which is $660^{\circ} \mathrm{C}$.

During the heating phase and before melting of the fuel occurs, a positive contribution to the reactivity might result from the decrease in density and, hence, the decrease in the self-shielding of the fuel." This change was estimated to be $\Delta k=+0.00 I$; the contribution was neglected in the calculation. If this additional reactivity were considered, the period would decrease in the course of the excursion from 20 seconds to nine seconds.

When the fuel reaches its melting point, it will deform. This deformation can only act to decrease the reactivity and halt the excursion, since the lattice spacing is chosen to give the minimum critical mass. 


\section{BIBLIOGRAPHY}

I. Cawley, W. E. "Using Boron-Trlfluorlde Gas for Reactor Control." Nucleonics 13, p. 30, August 1955. (A picture and description of the "T35 Test pile" appear on p. 31).

2. Axtmann, R. C., Dessauer, G., and Parkinson, T. F. Reactivity Measurements in a Subcritical Pile. E. I. du Pont de Nemours and Co. DP-48, November 1955.

3. Physics Division Semiannual Progress Report for period ending September 10, 1954. Oak Ridge National Laboratory. ORNL-1820.

4. Lapsley, A. C. Differential Electrometer. E. I. du Pont de Nemours and Co. DP-95, December 1954.

5. Rossi, B. B. and Staub, H. H. Ionization Chambers and Counters. New York: McGraw-Hili Book Co. 1949. 


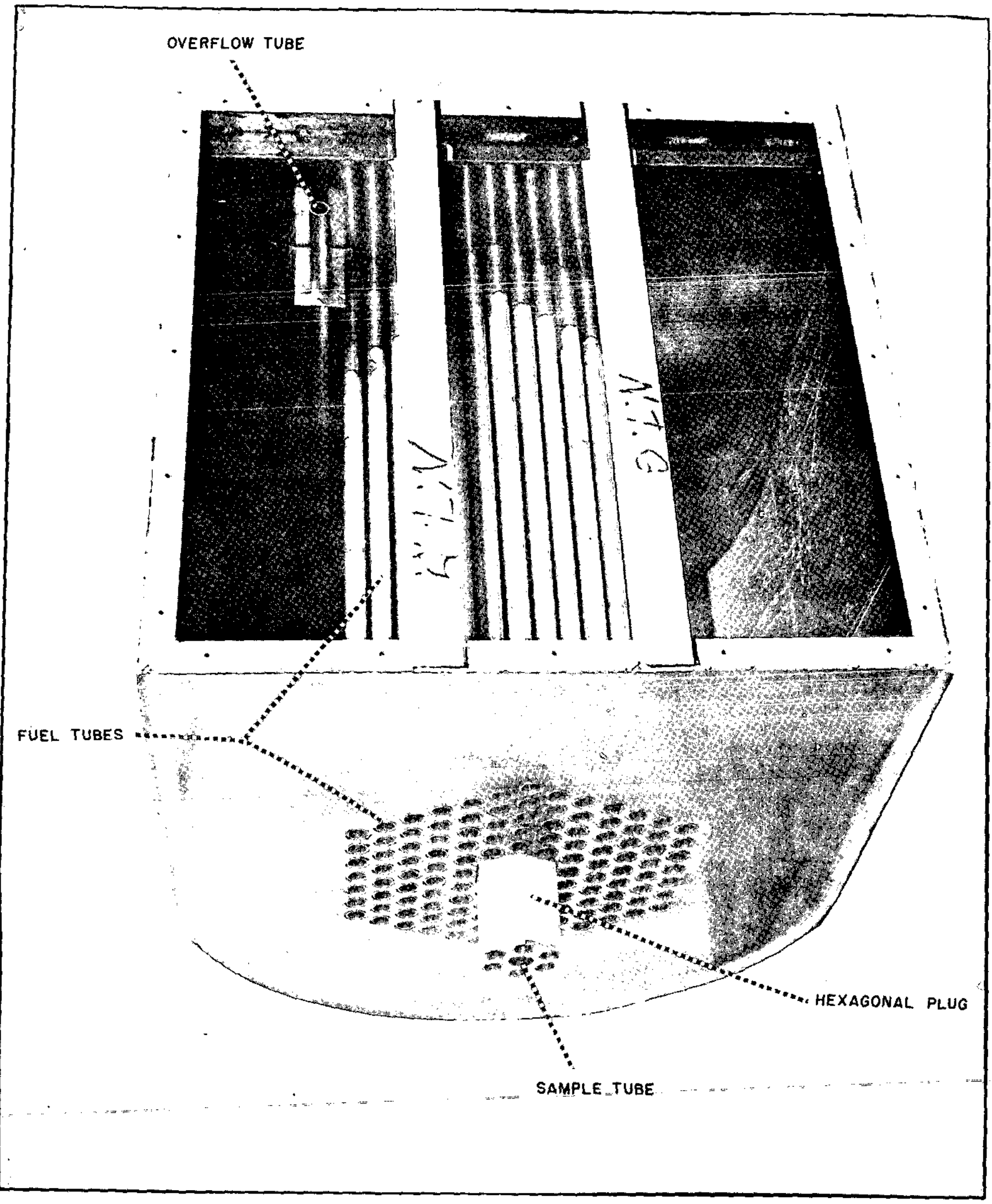

TANK, TOP VIEW

$\because ?$

$\therefore$ 政

37 


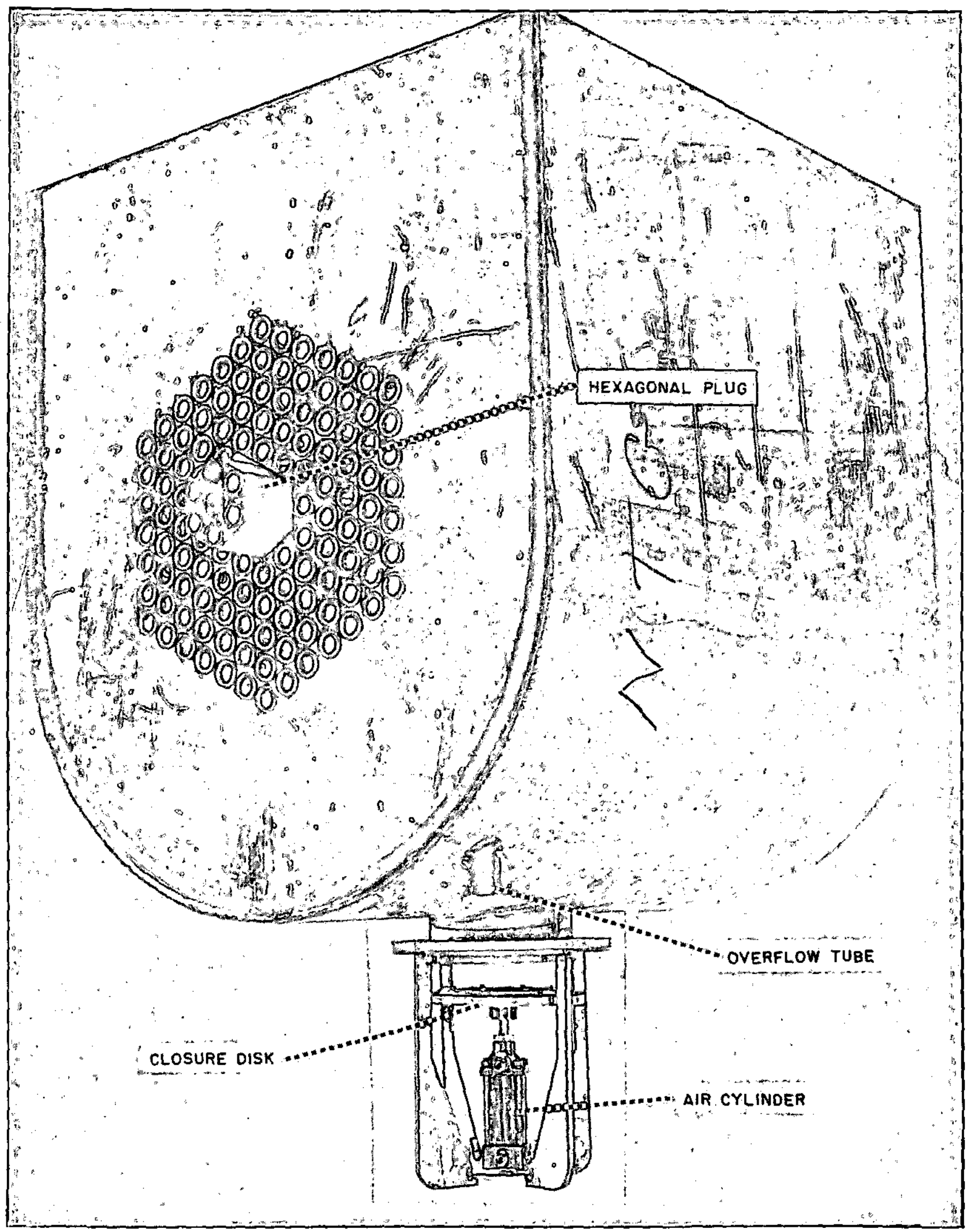

TANK AND DUMP VALVE ASSEMBLY

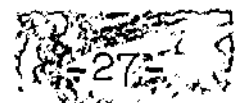

$$
\begin{aligned}
& \begin{array}{l}
367 \\
36
\end{array}
\end{aligned}
$$




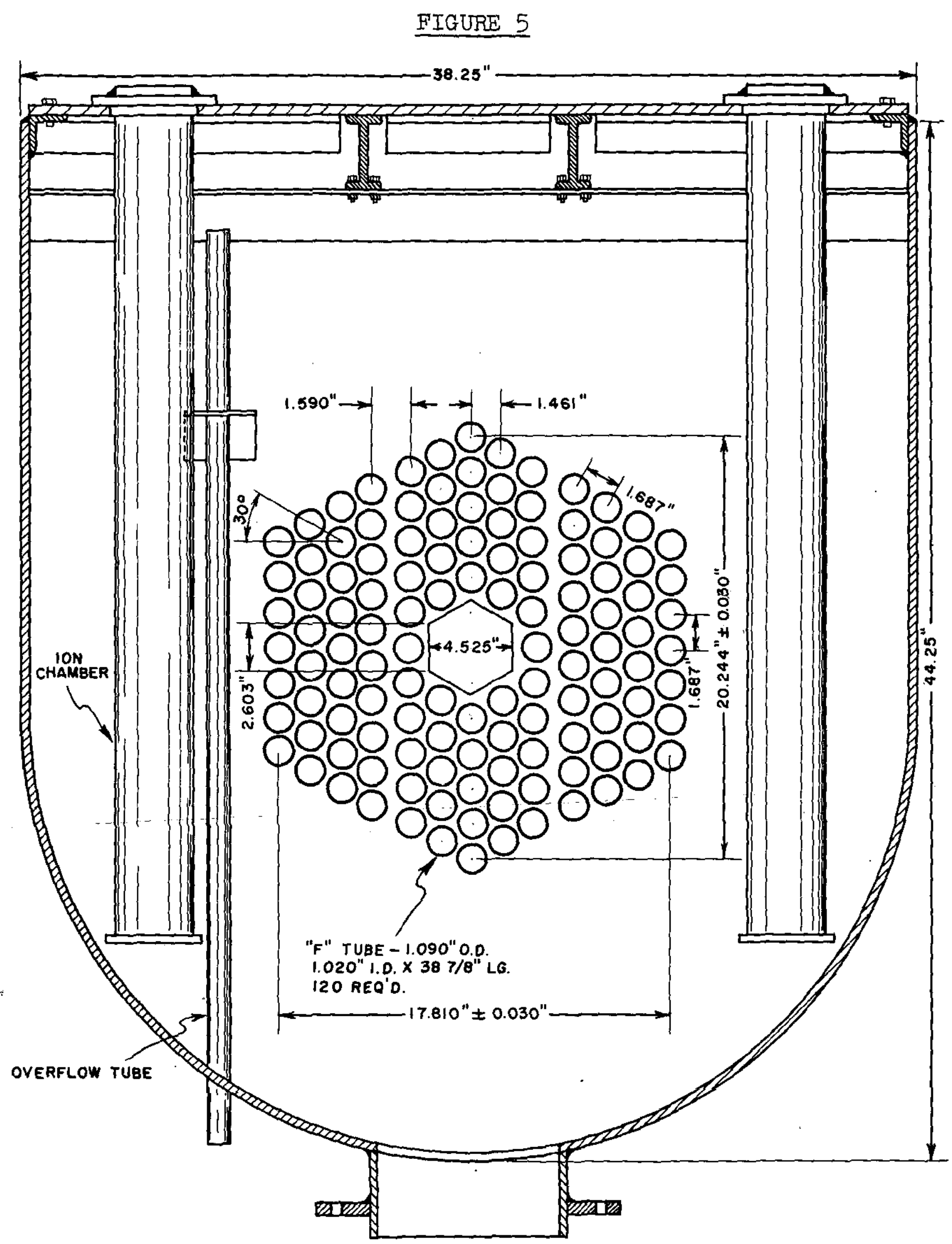

TANK DETAILS 
FIGURE 6

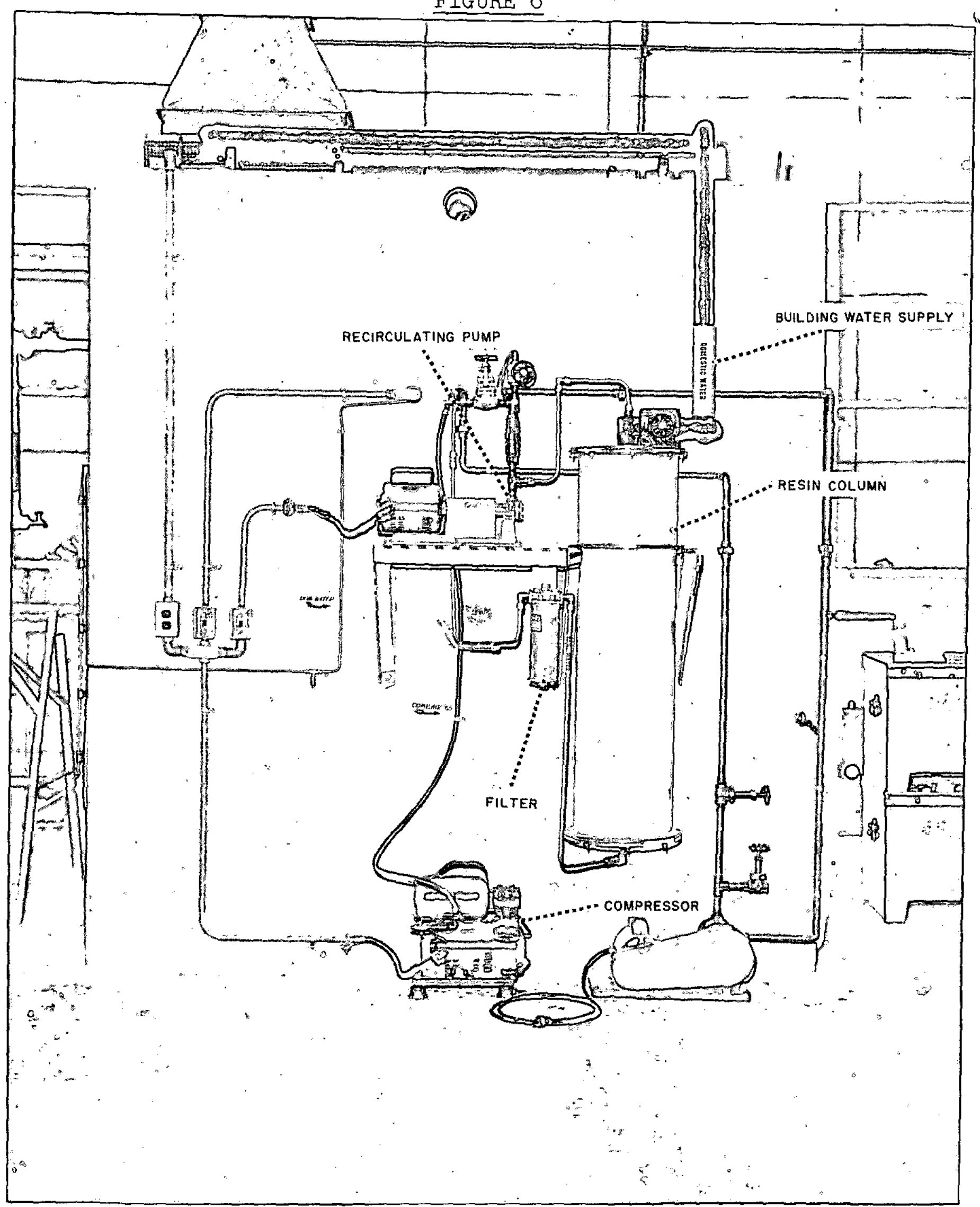

MODERATOR SYSTEM

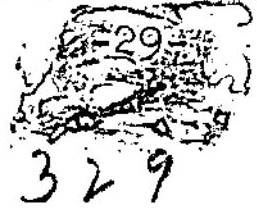




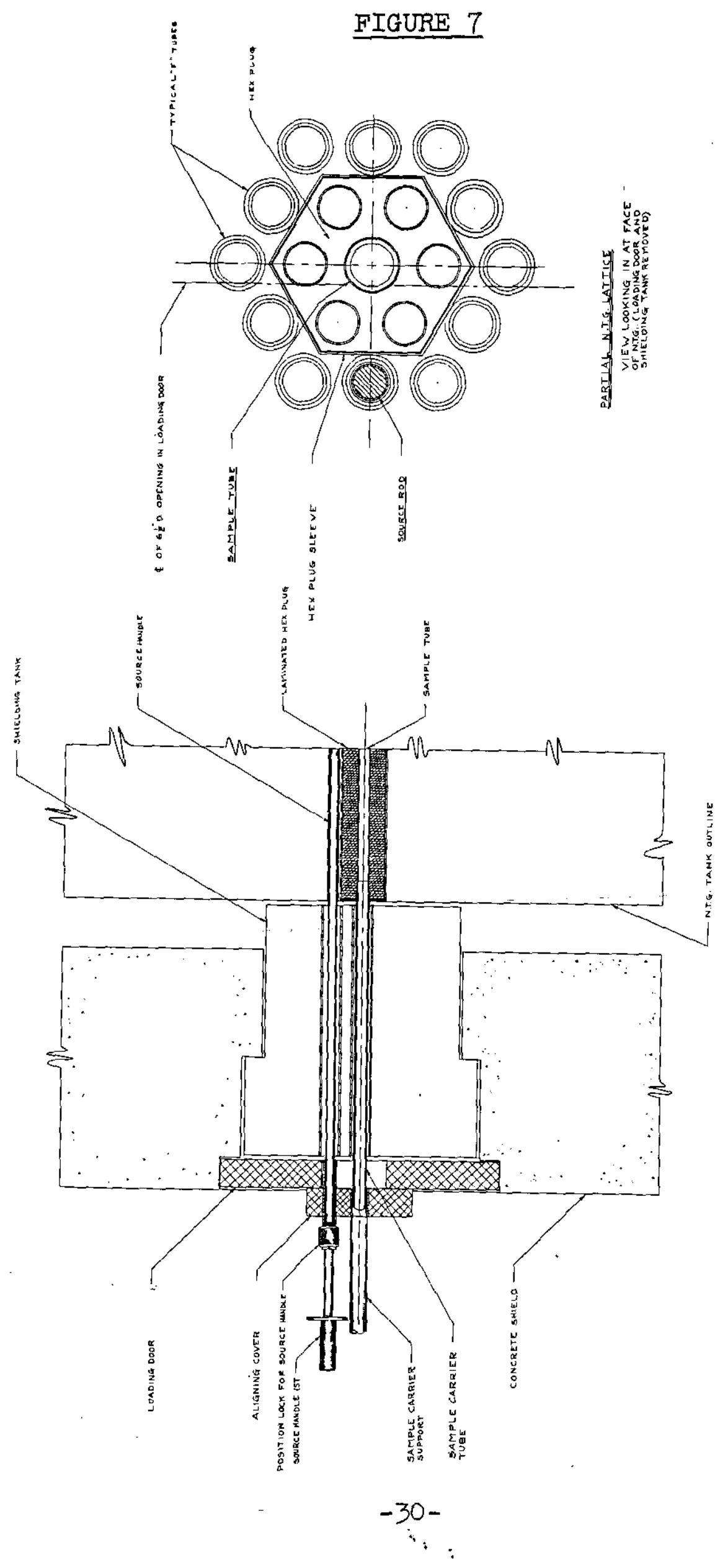

그. 


\section{FIGURE 8}

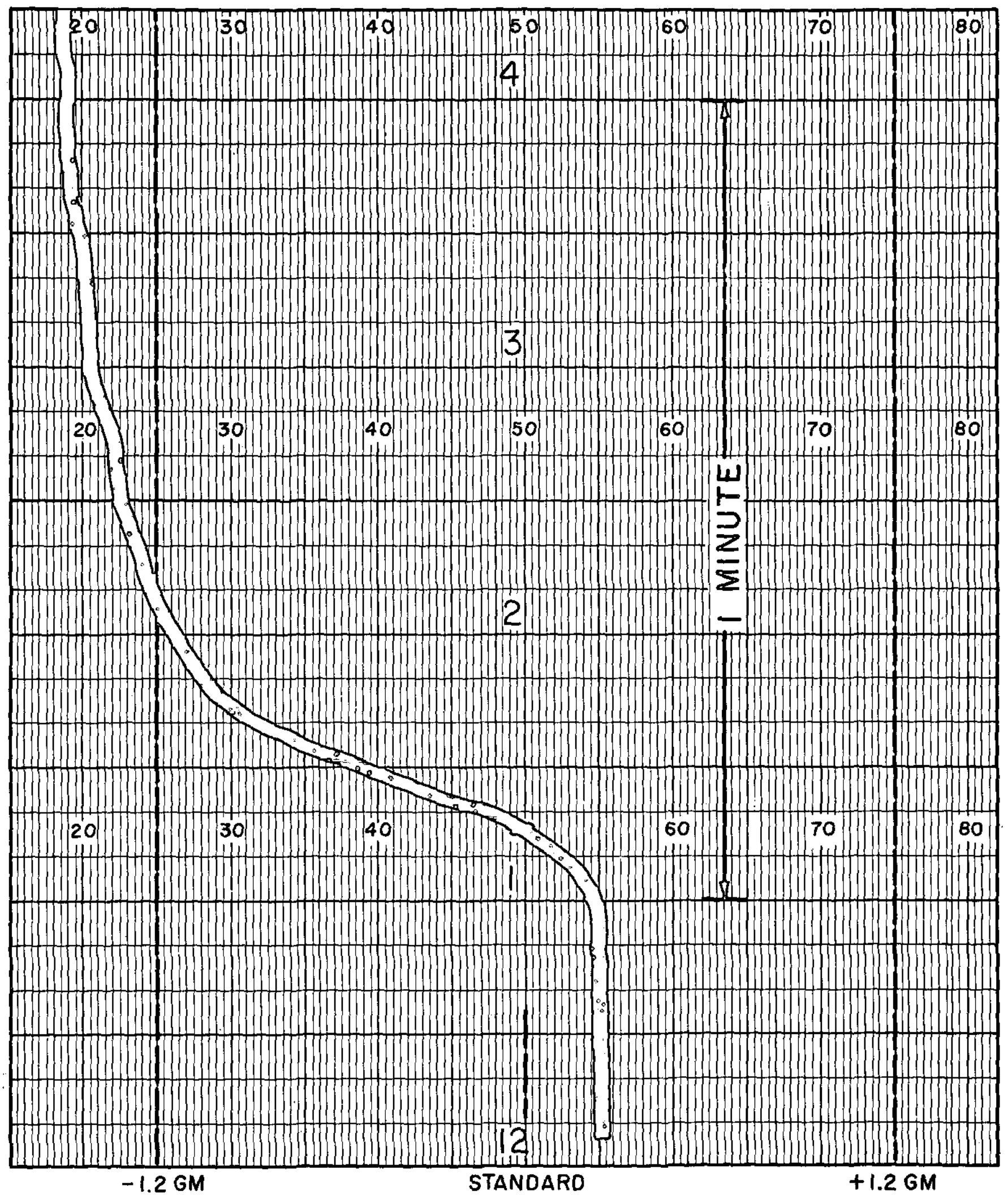

IYPICAL SECTION OF RECORDER CHARI 


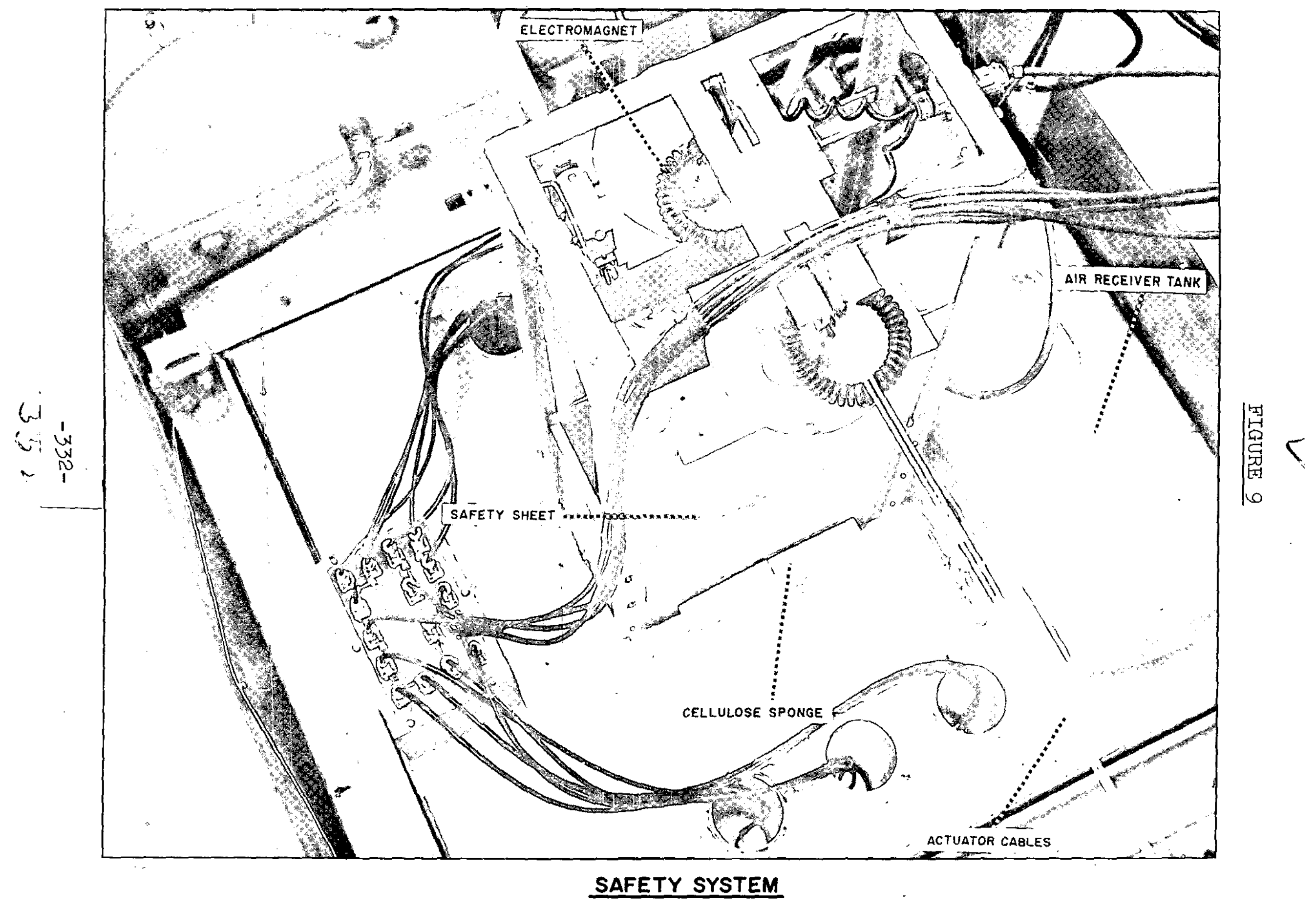


FIGURE 10

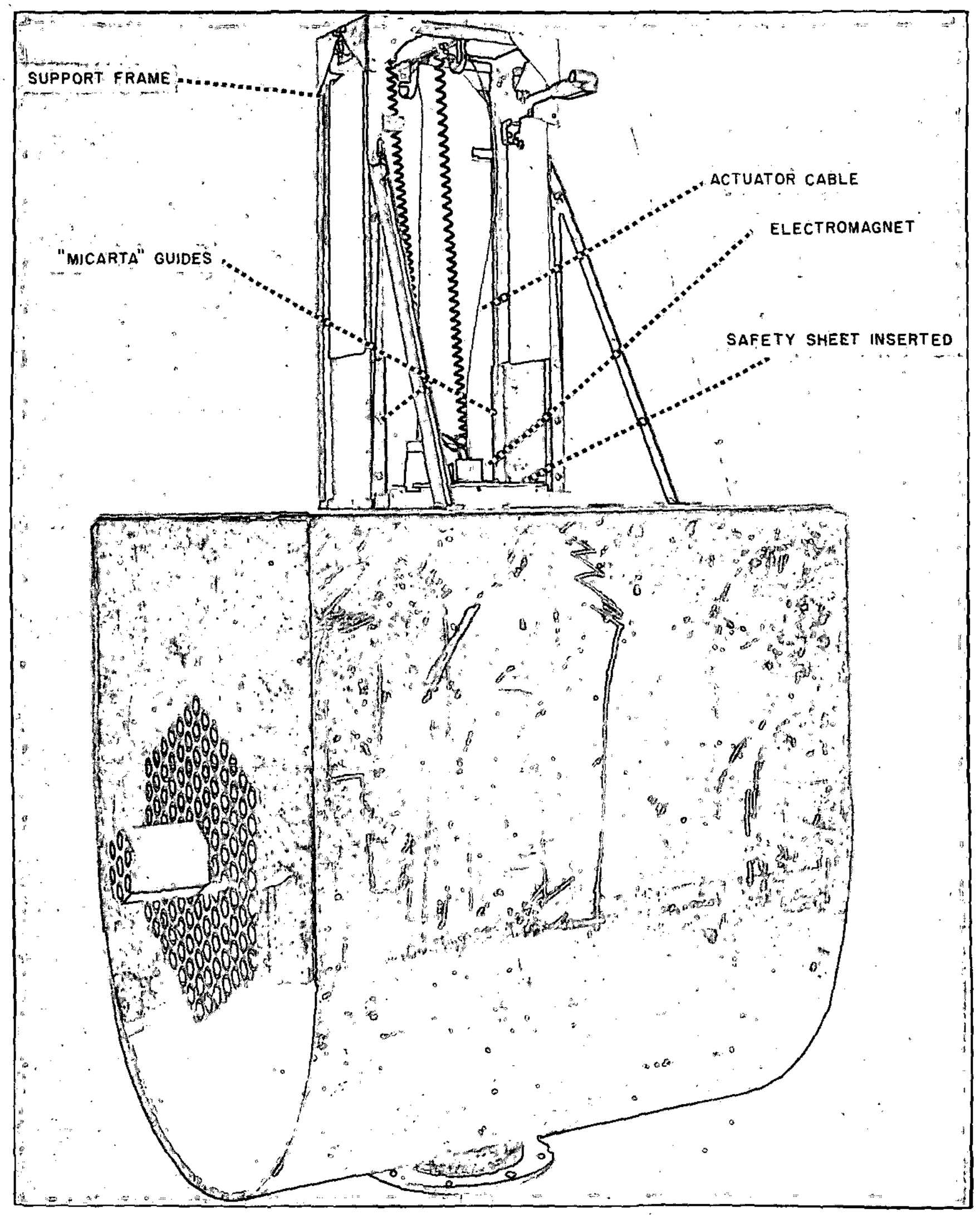

SUPPORT FRAME FOR SAFETY SHEETS

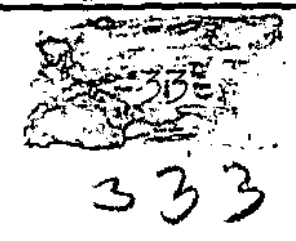




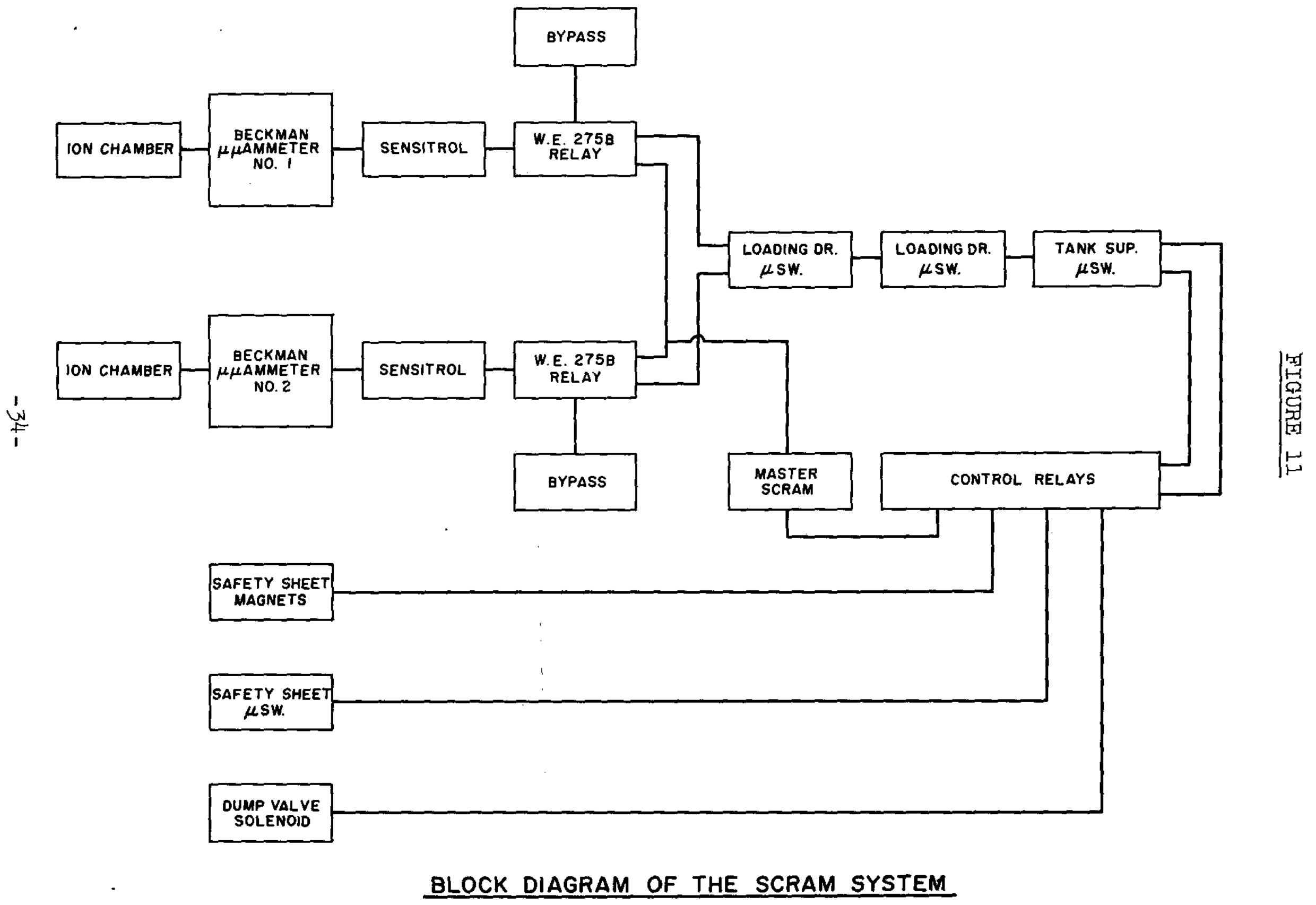


FIGURE 12

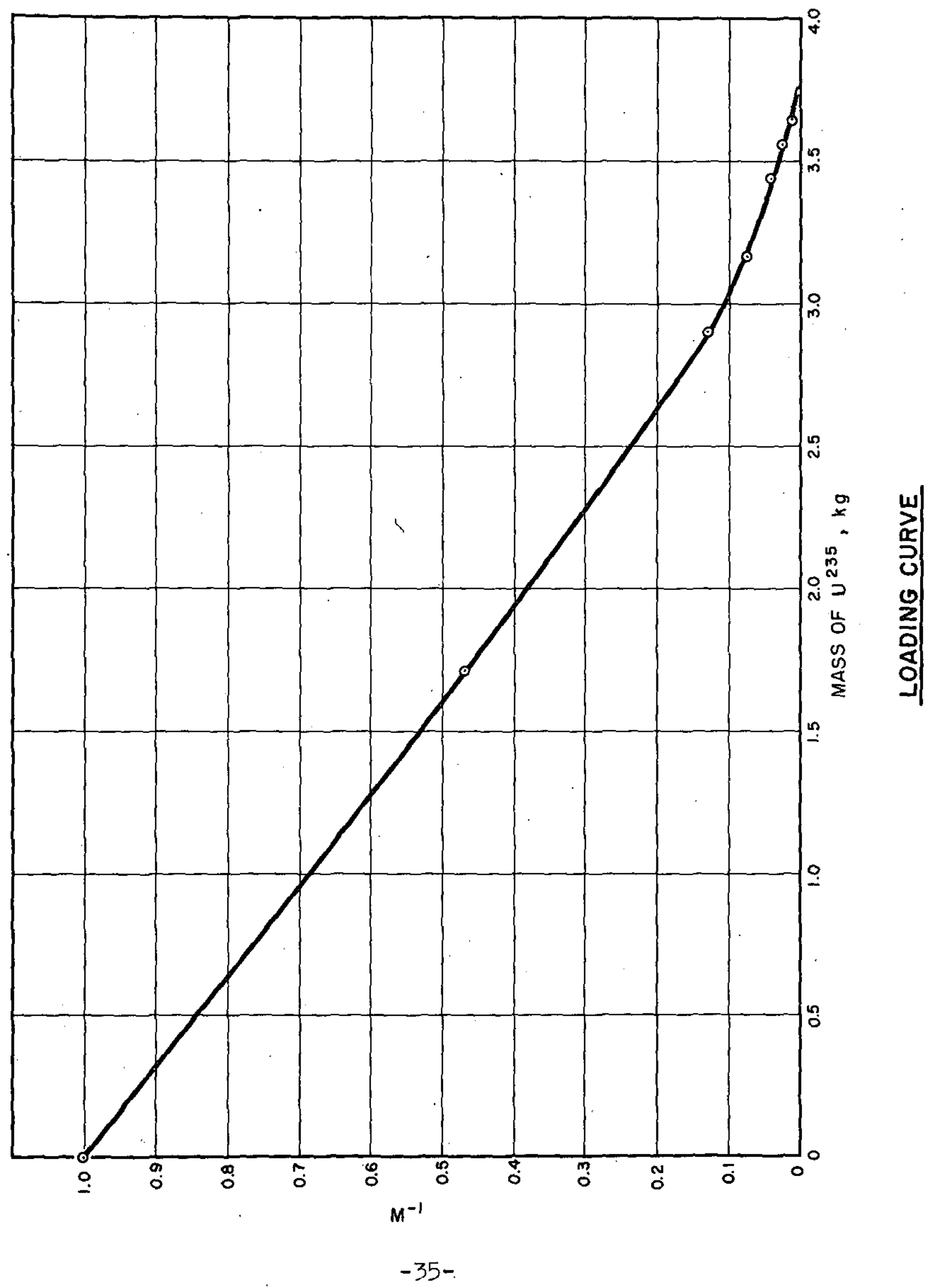




\section{FIGURE 13}

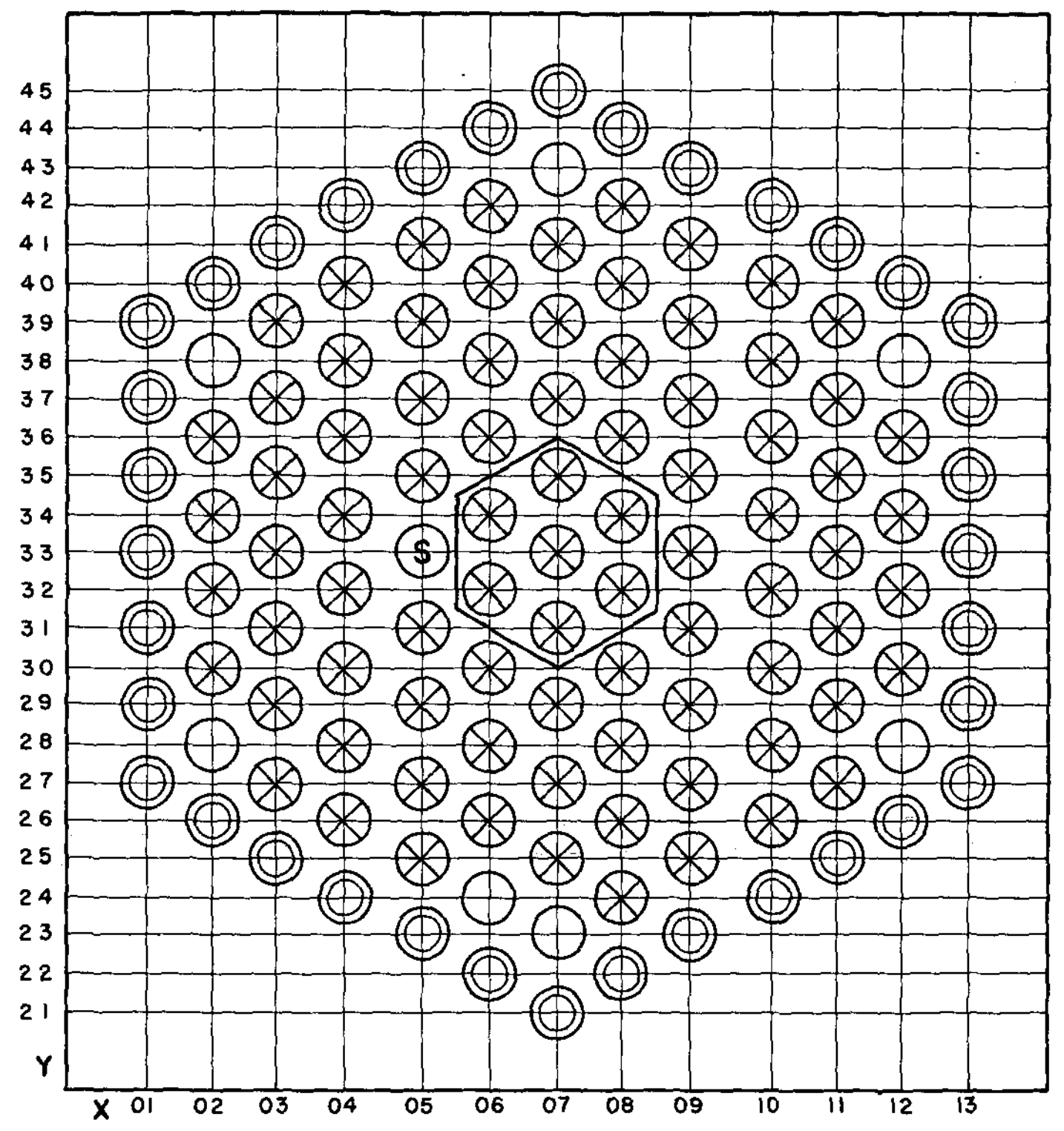

$\bigotimes$ fuel
(O) Plastic
(S) source

LATTICE CONFIGURATION FOR $k=0.990$ 


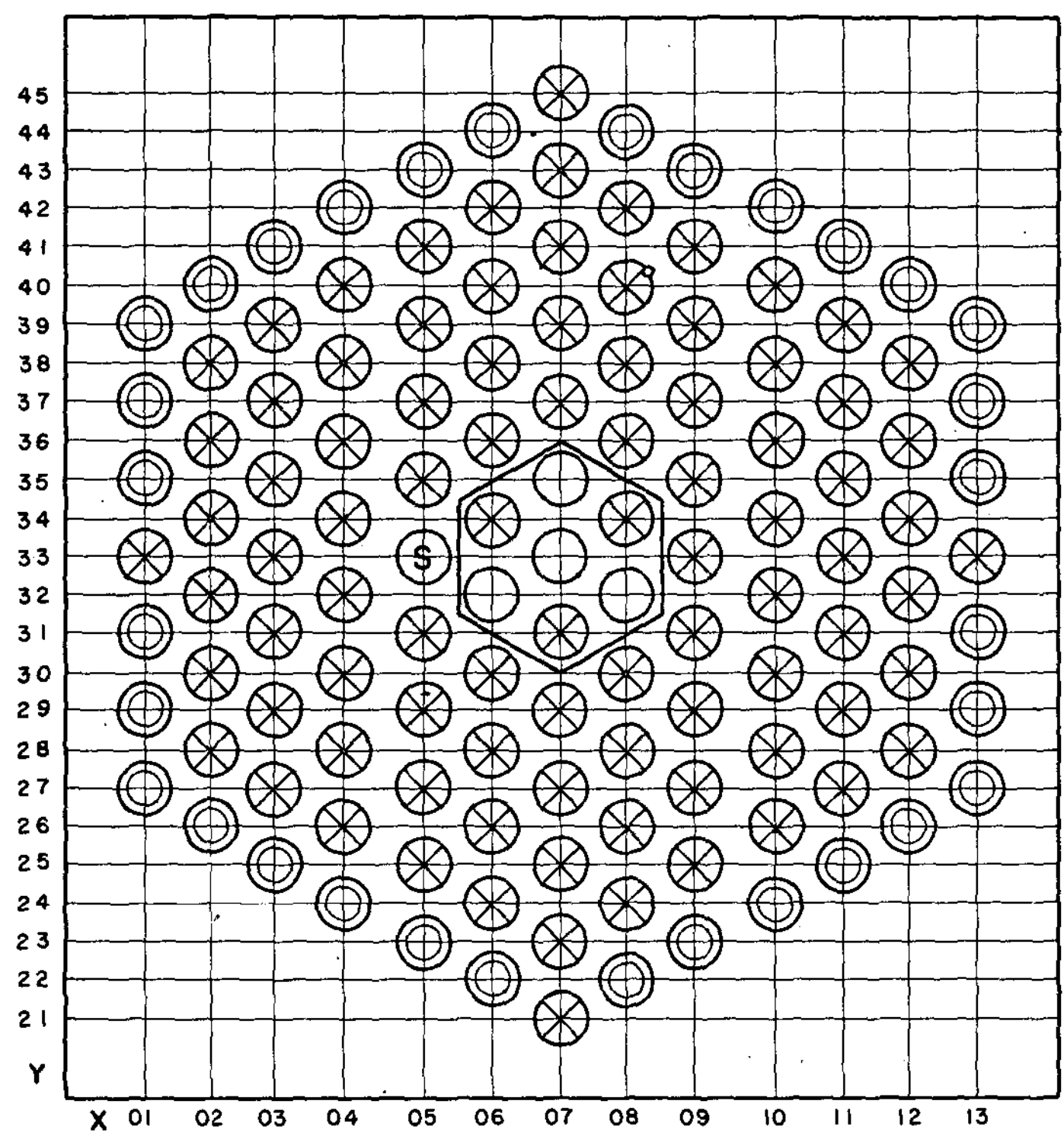
$\otimes$ fuel
(O) PLASTIC
(s) SOURCE

LATTICE CONFIGURATION FOR TESTING SLUGS OF ENRICHED URANIUM-ALUMINUM ALLOY 
FIGURE 15

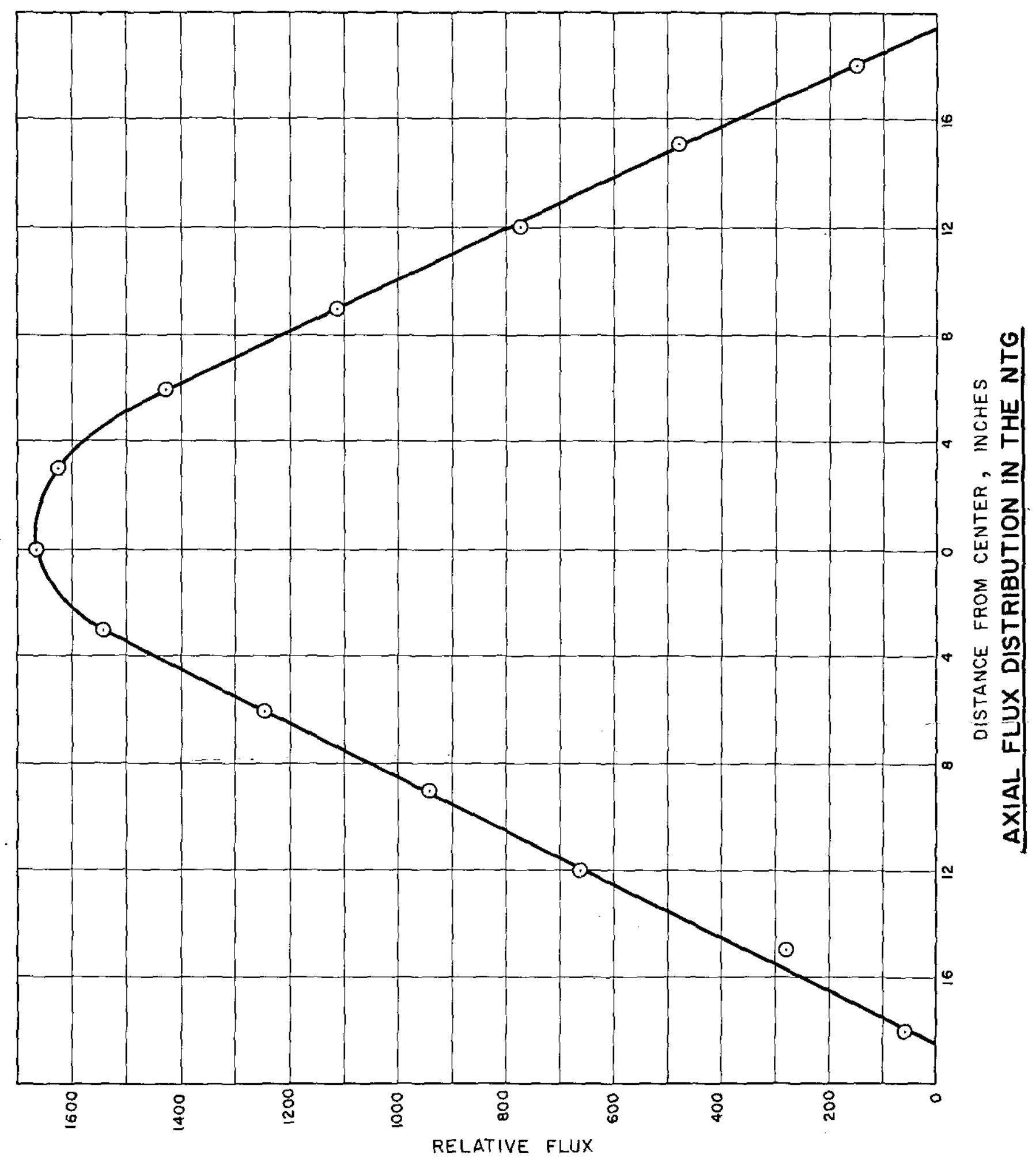




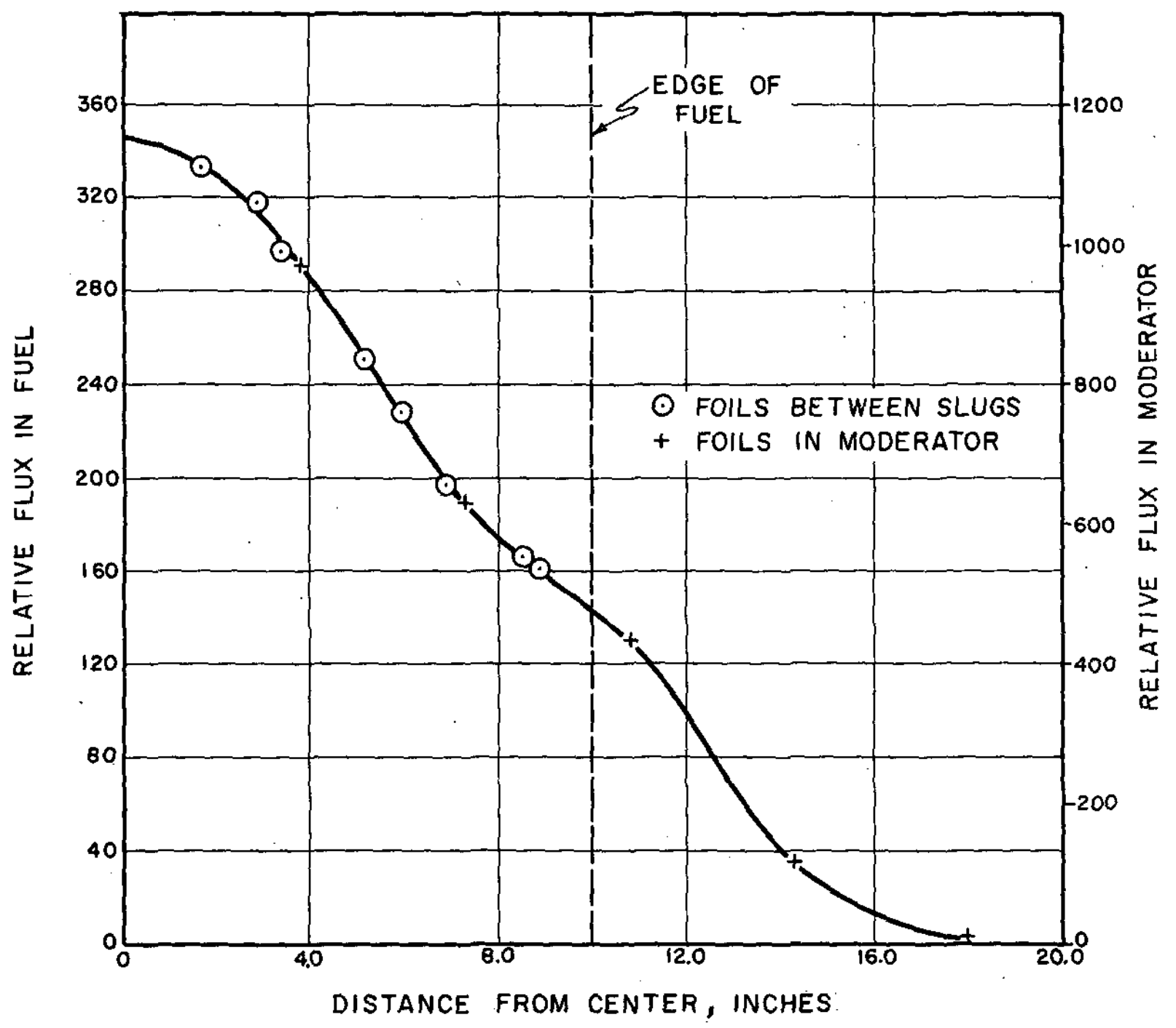

RADIAL FLUX DISTRIBUTION IN THE NTG 


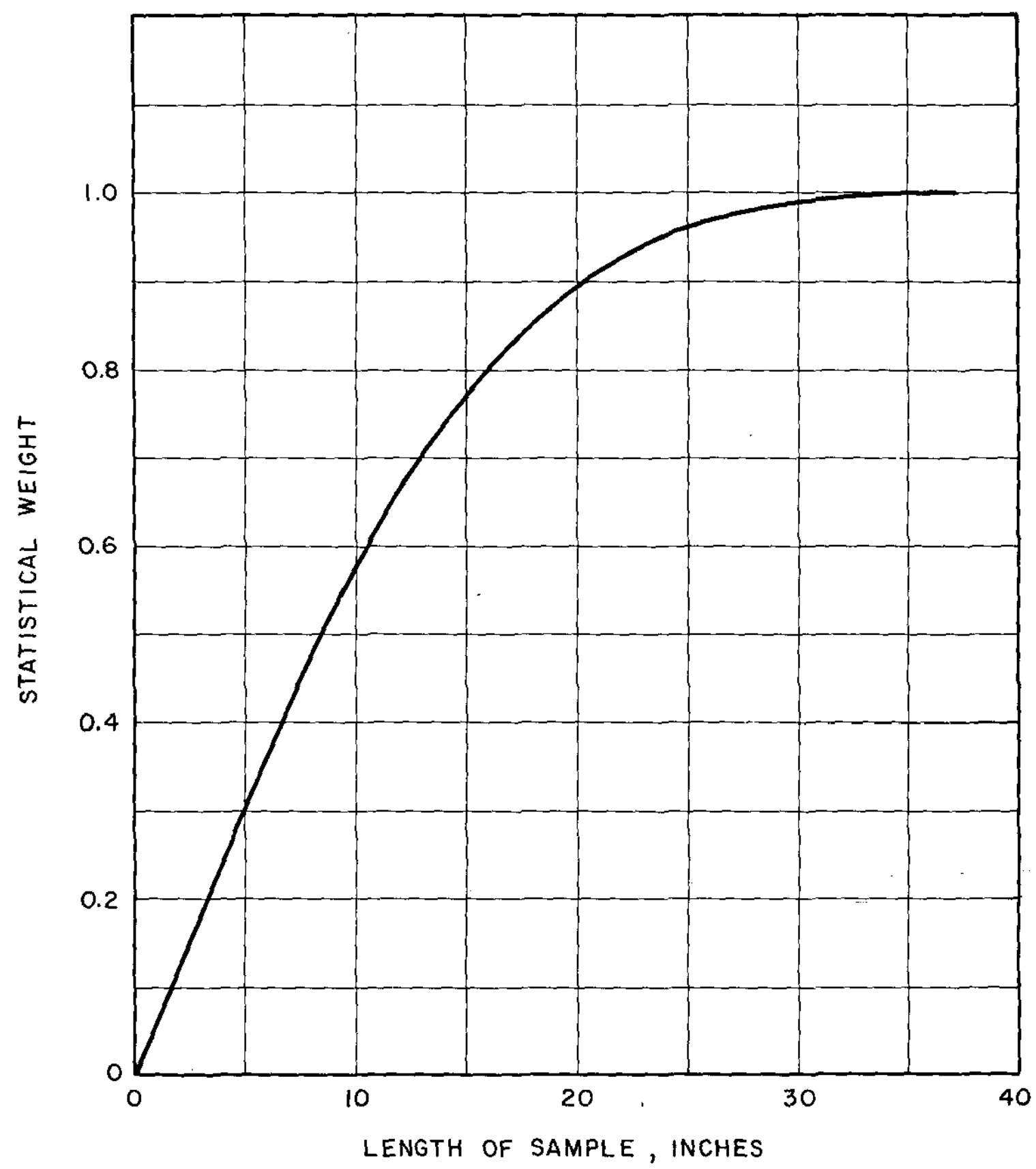

EFFECT OF SAMPLE LENGTH ON $k$

$-40-$ 
FIGURE I8

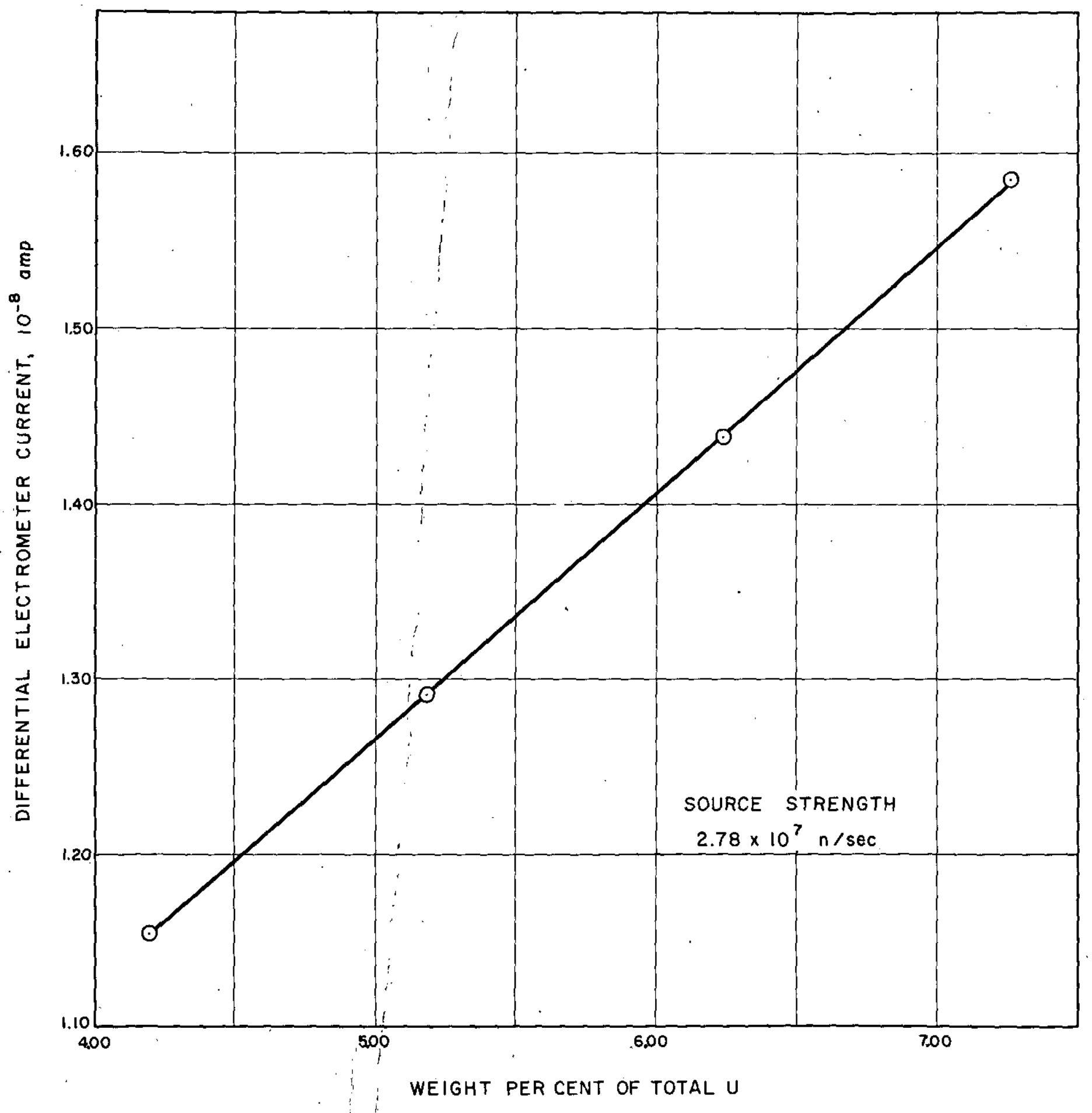

CALIBRATION FOR' SLUGS OF ENRICHED URANIUM-ALUMINUM ALLOY CONTAINING FOUR TO SEVEN PER CENT BY WEIGHT URANIUM 


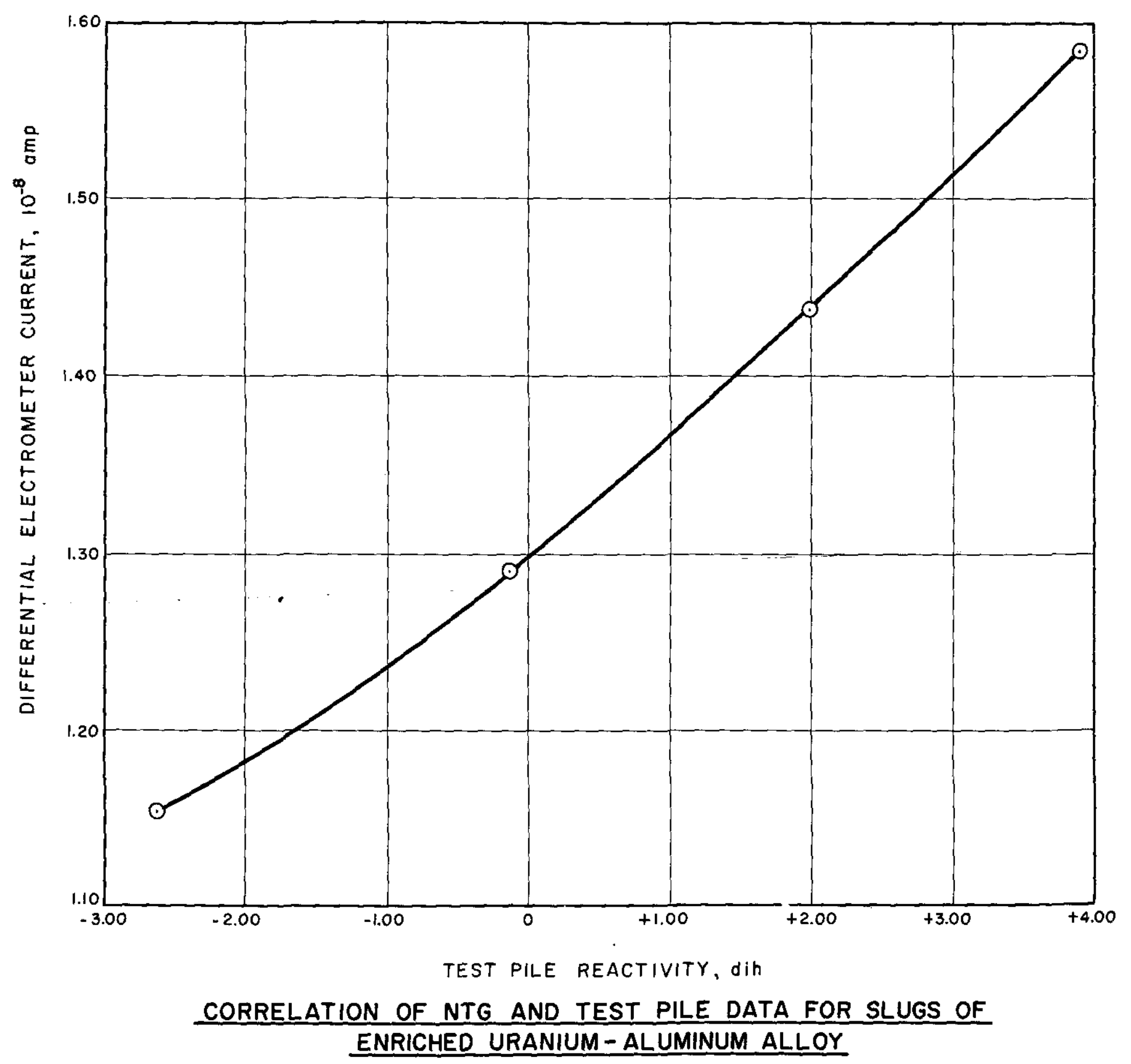

CONTAINING FOUR TO SEVEN PER CENT BY WEIGHT URANIUM 


\section{FIGURE 20}

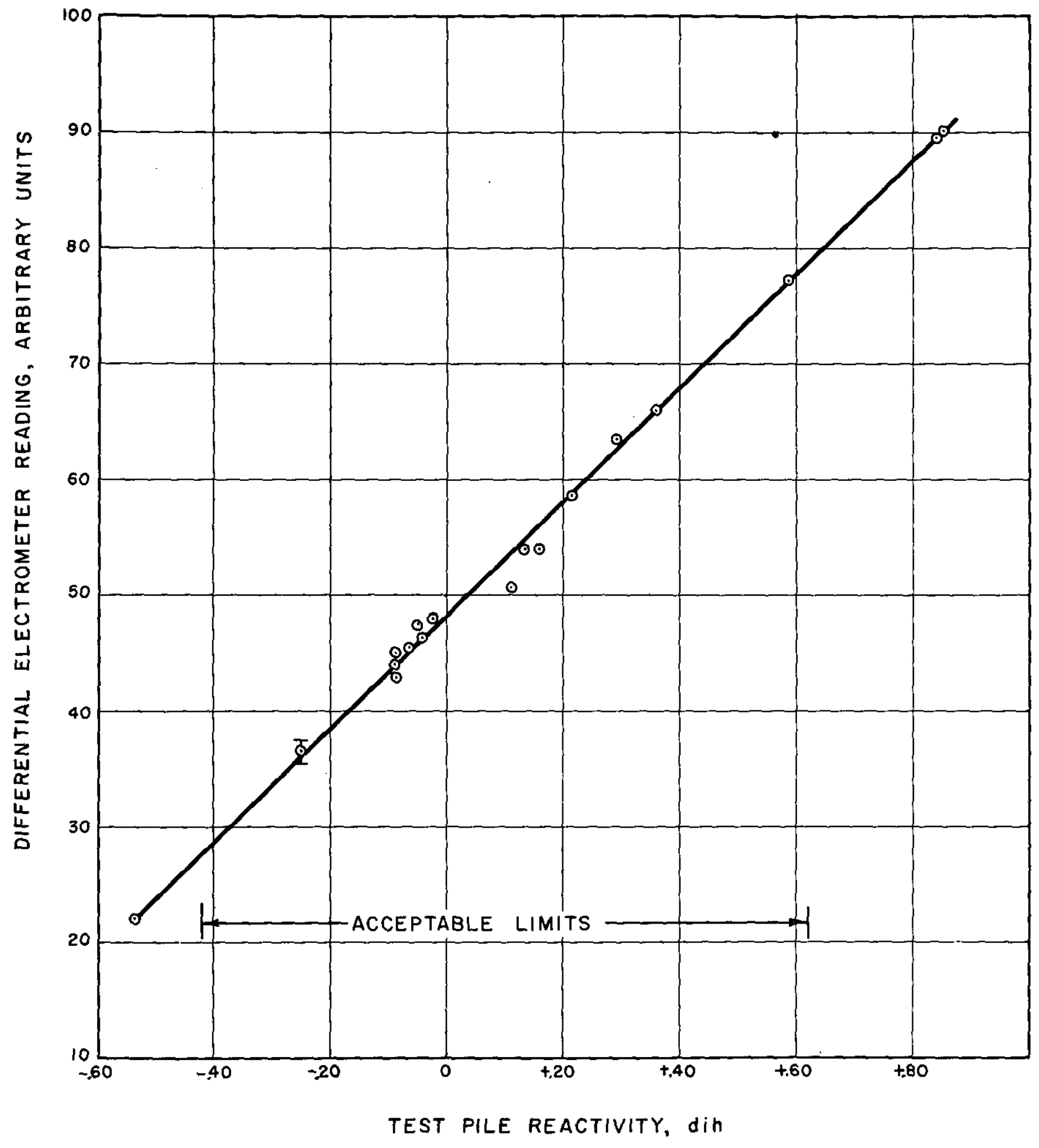

CORRELATION OF NTG AND TEST PILE DATA FOR SLUGS OF ENRICHED URANIUM-ALUMINUM ALLOY

SLUGS NOMINALly fiVe PER CENT BY WEIGHT URANIUM 


\section{FIGURE 21}

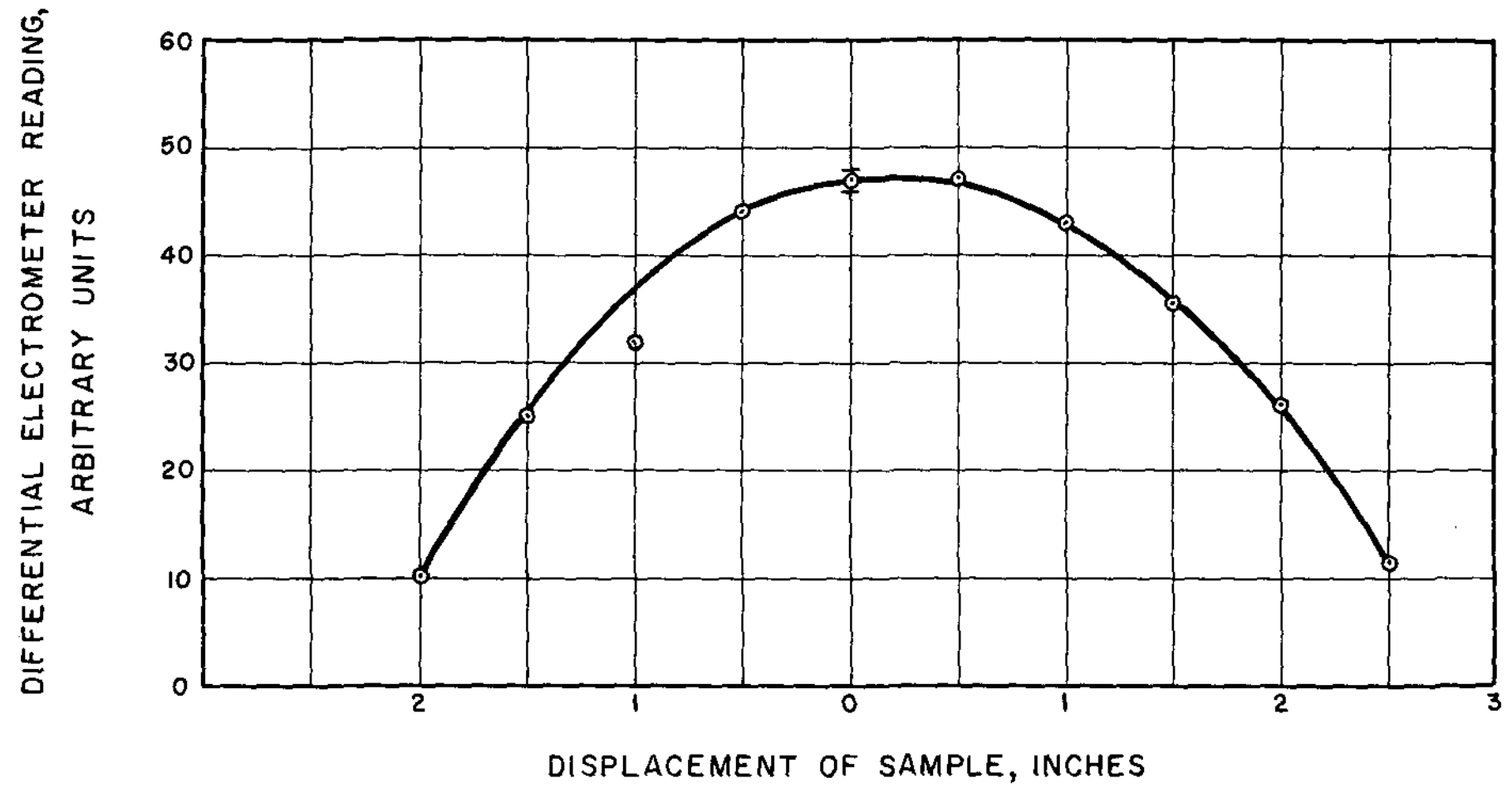

EFFECT OF DISPLACING SAMPLE FROM

THE CENTER OF THE CORE 


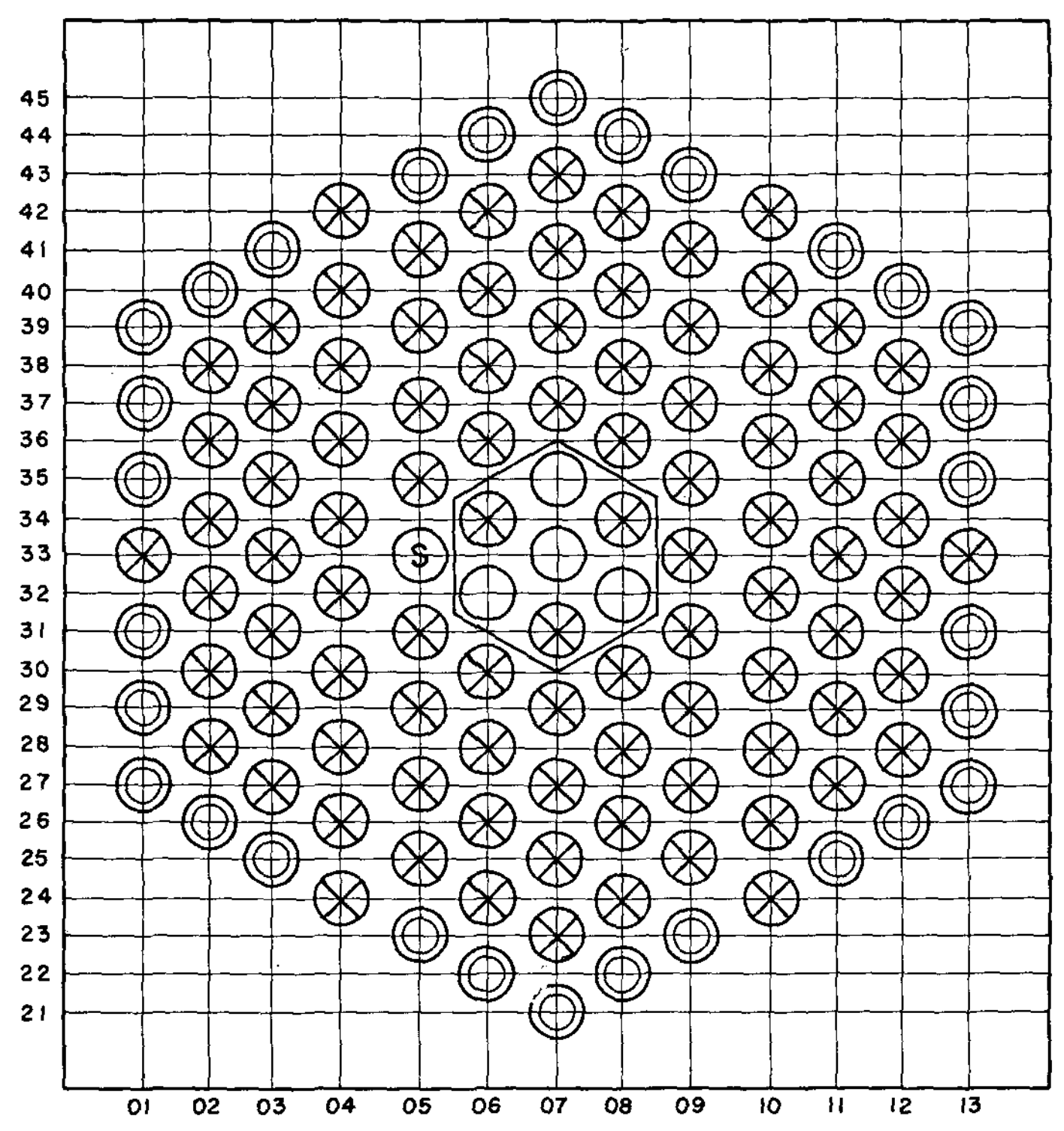
$\bigotimes$ fuel
(2) PLASTIC
(S) Source

LATTICE CONFIGURATION FOR TESTING NATURAL URANIUM SLUGS AND LITHIUM-ALUMINUM SLUGS 


\section{FIGURE 23}

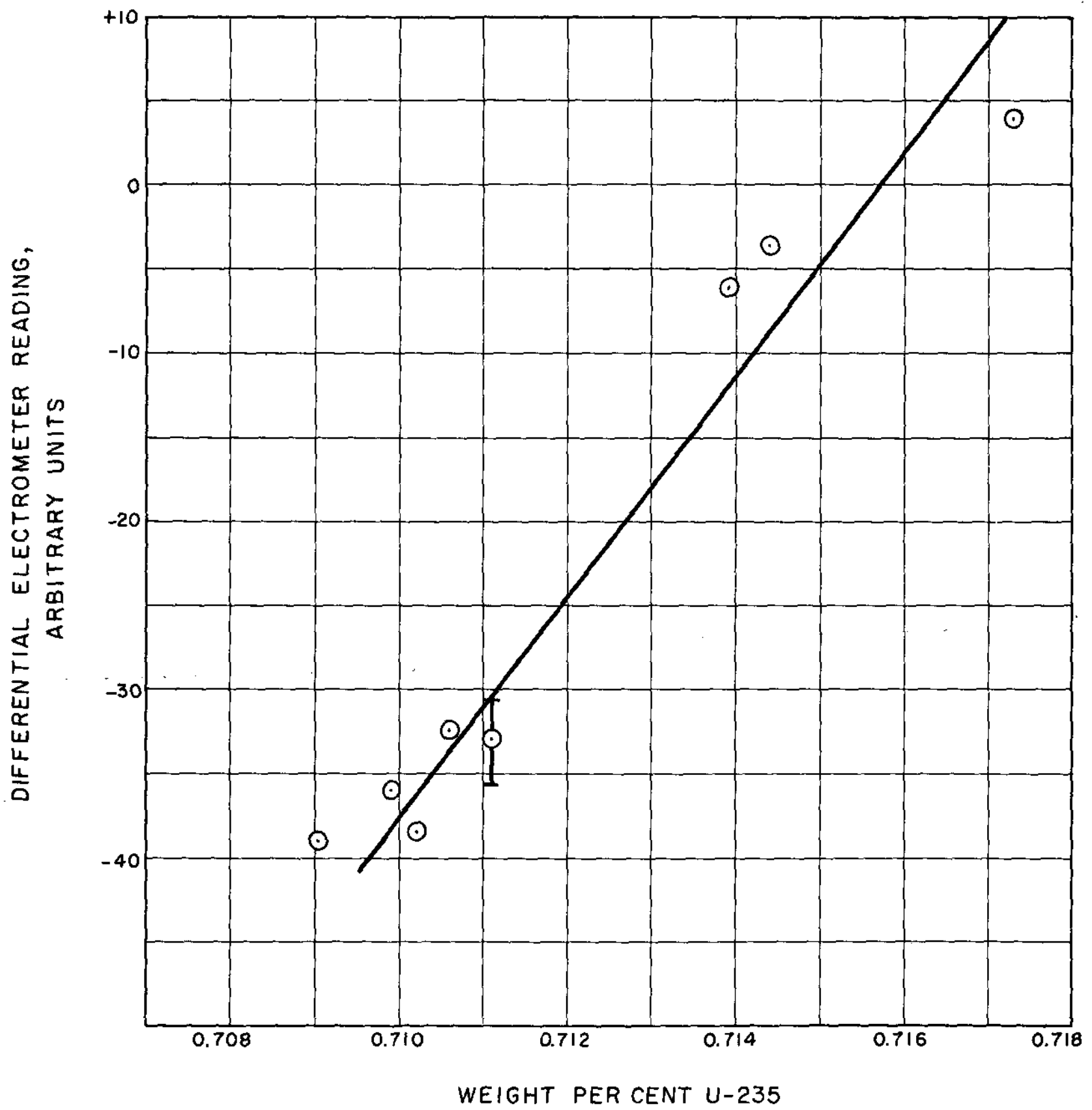

CALIBRATION FOR NATURAL URANIUM SLUGS 


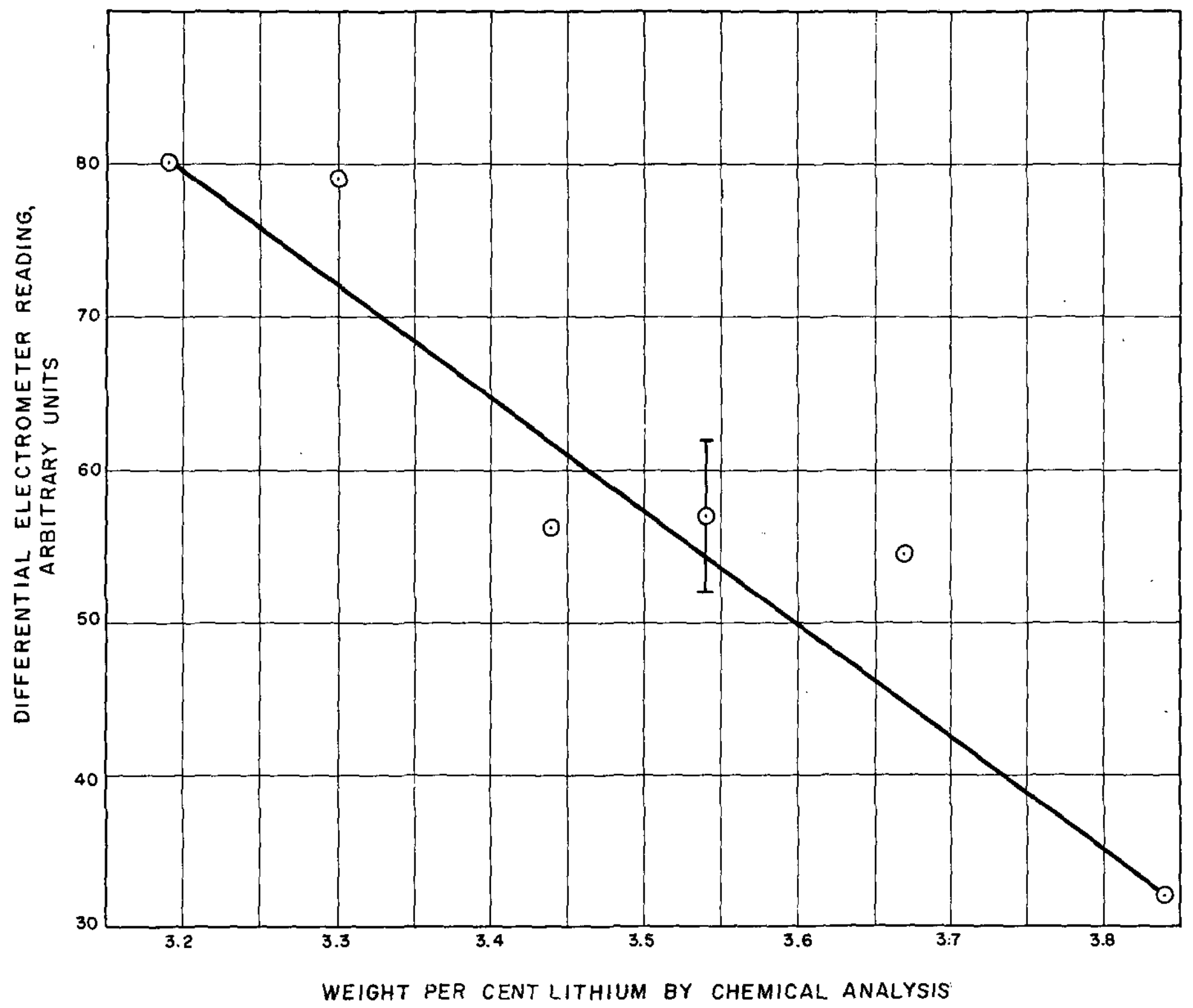

CALIBRATION FOR SLUGS OF LITHIUM-ALUMINUM ALLOY 


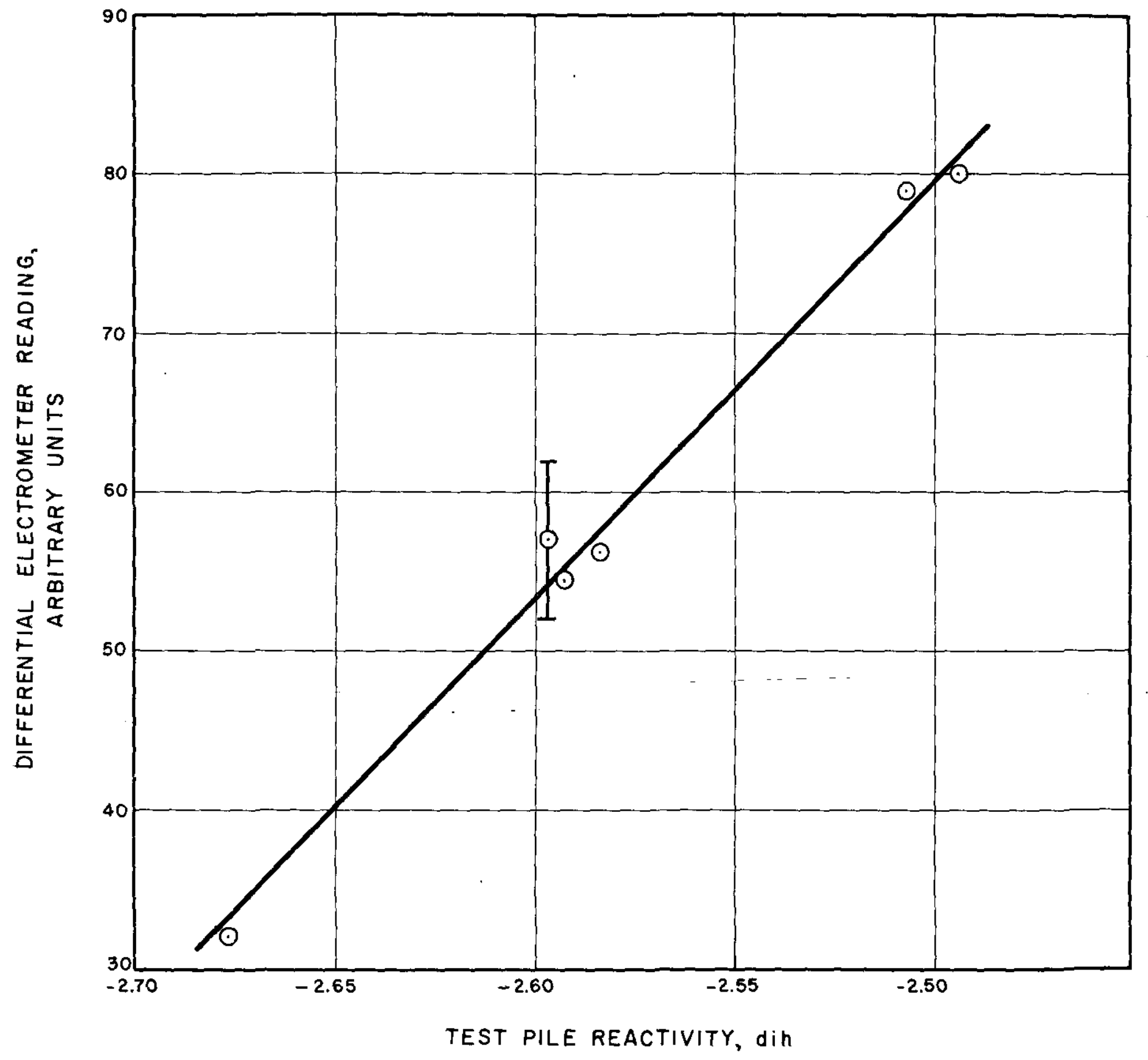

CORRELATION OF NTG AND TEST PILE DATA FOR SLUGS OF LITHIUM-ALUMINUM ALLOY 


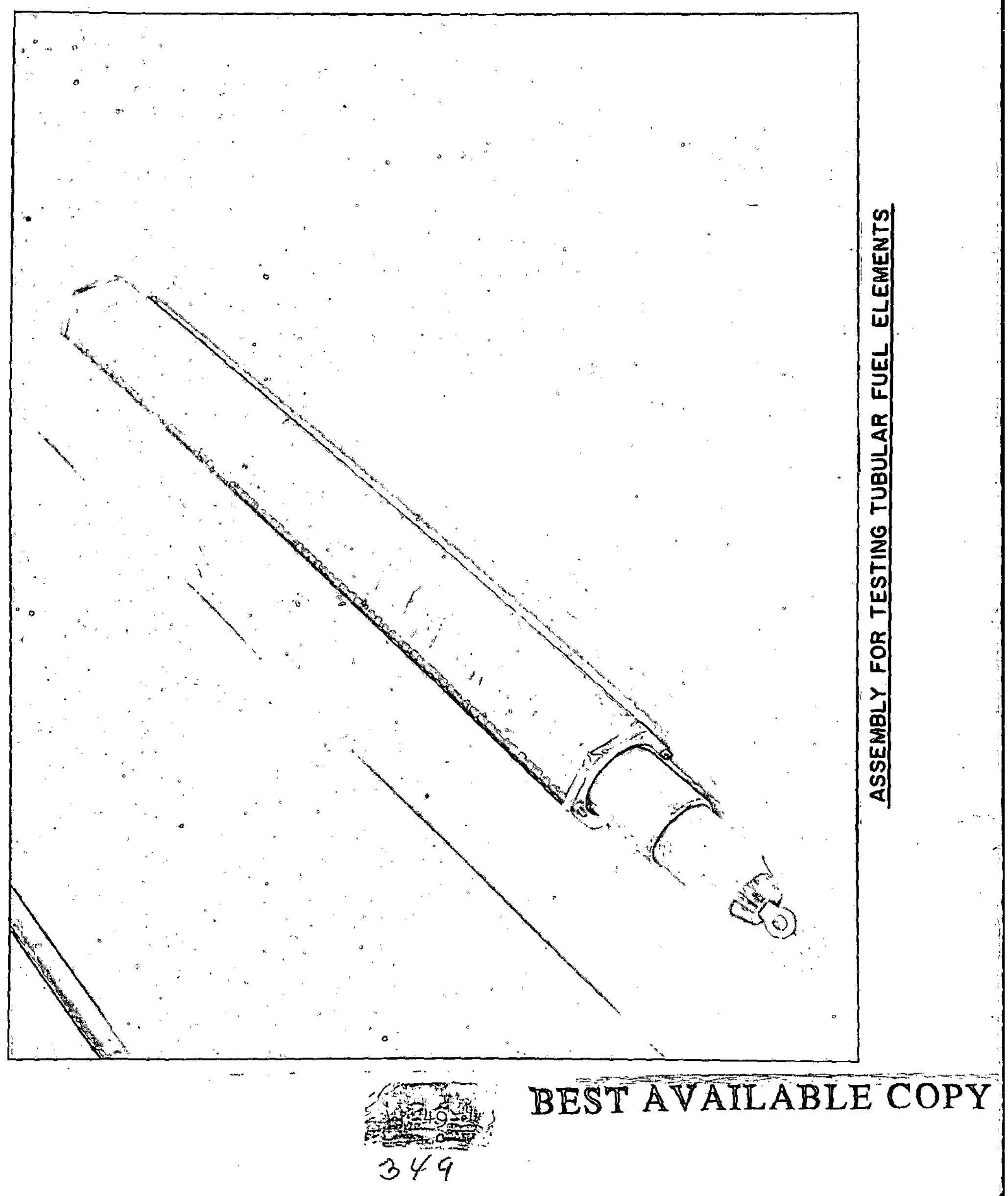




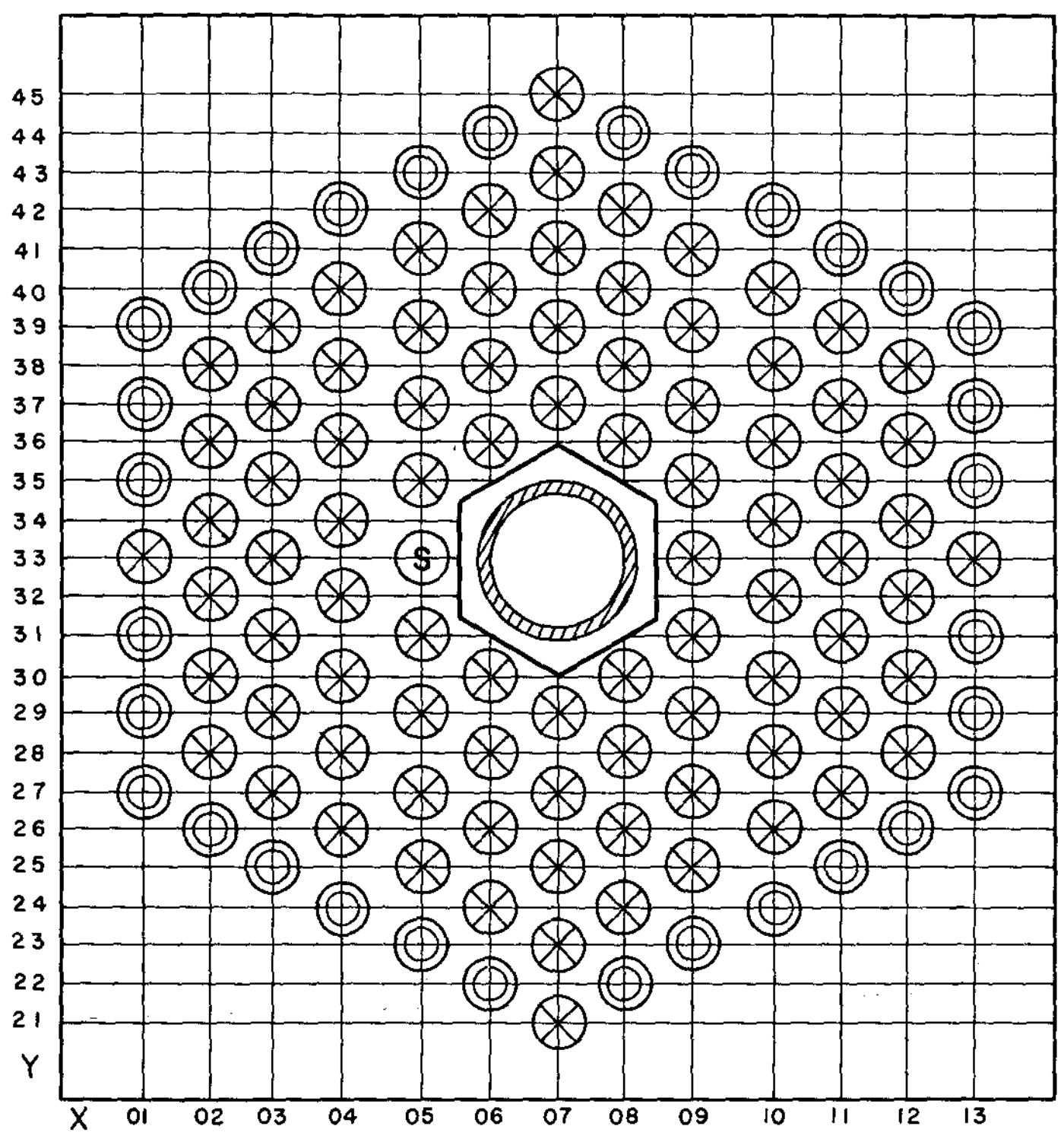

(8) Fuel
(C) plastic
(5) Source

LATTICE CONFIGURATION FOR TESTING TUBES OF ENRICHED URANIUM - ALUMINUM ALLOY 


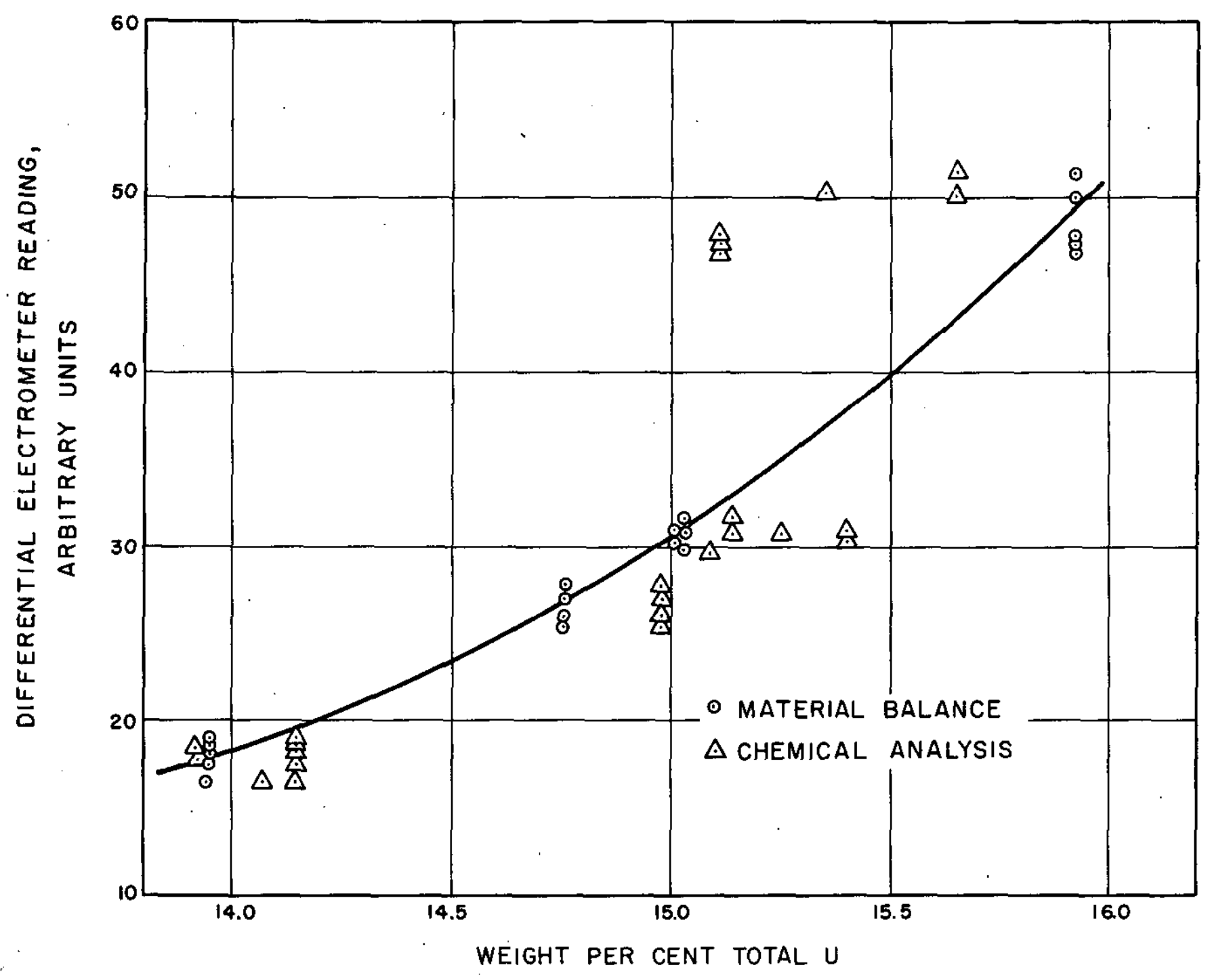

CALIBRATION FOR TUBES

OF ENRICHED URANIUM - ALUMINUM ALLOY 
FIGURE 29

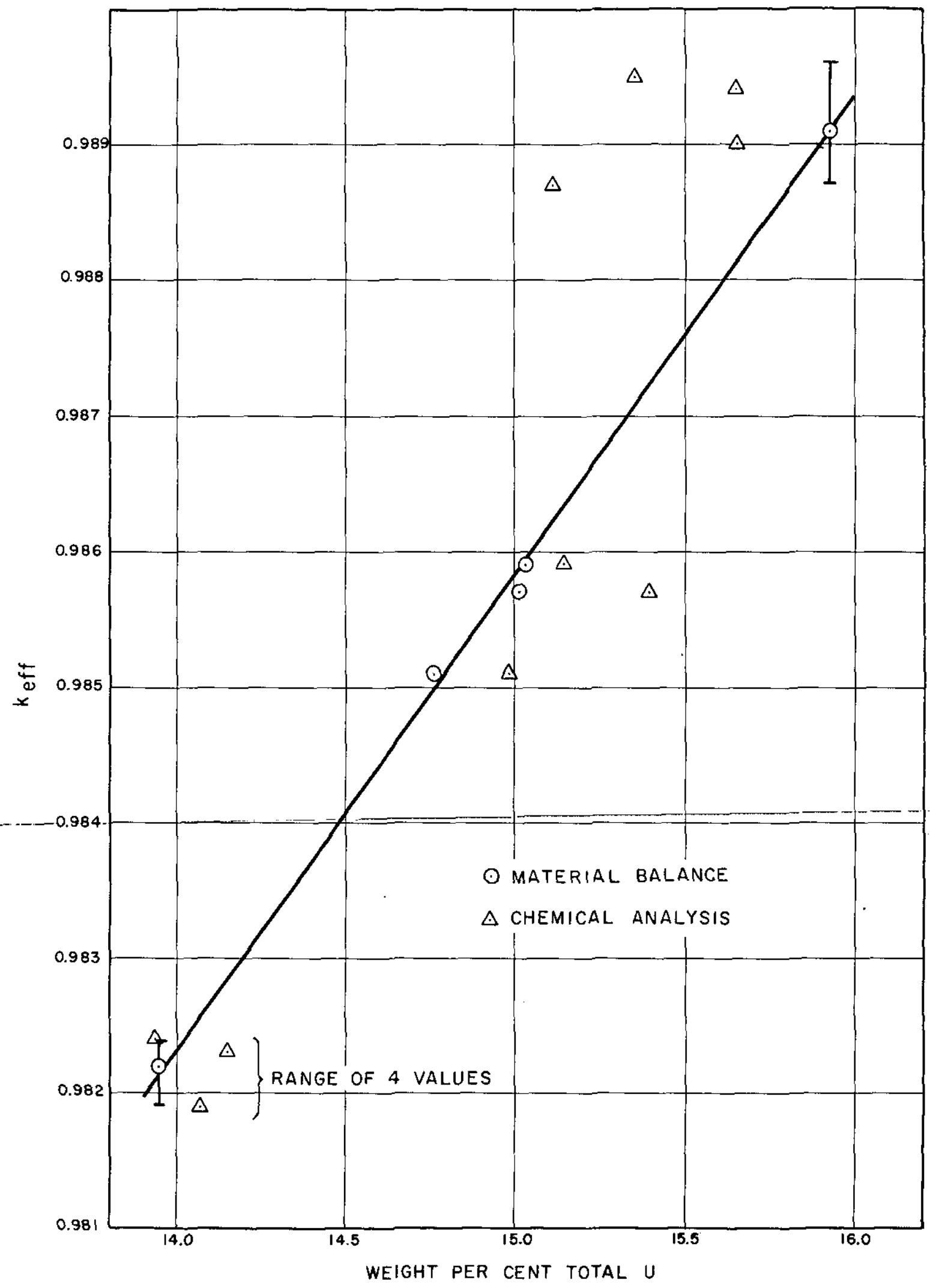

EFFECT OF ENRICHED TUBES ON THE

EFFECTIVE MULTIPLICATION CONSTANT 


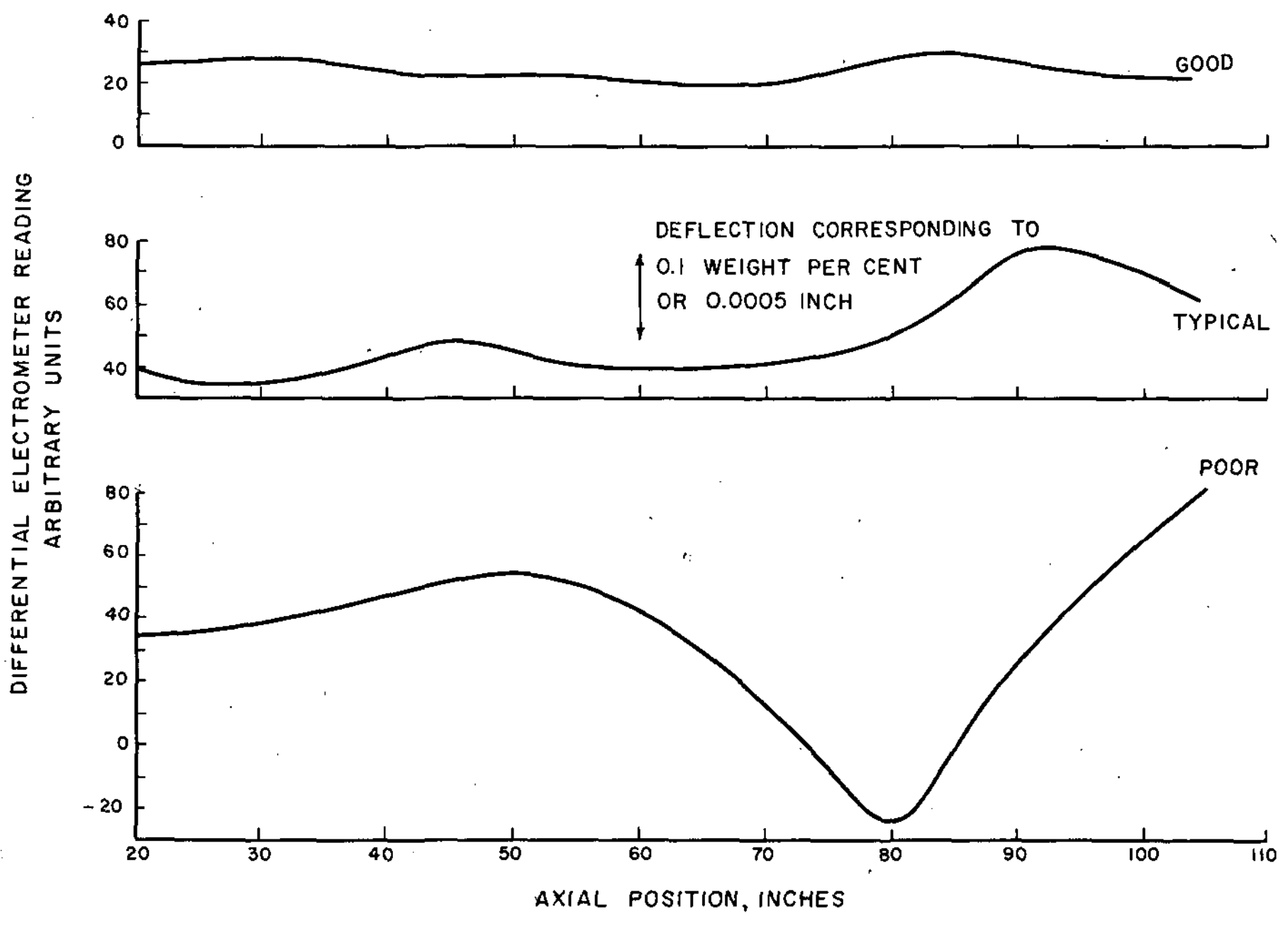

AXIAL TRAVERSES OF TUBULAR ELEMENTS

$-53-\therefore$ 
$\checkmark$

FIGURE 31

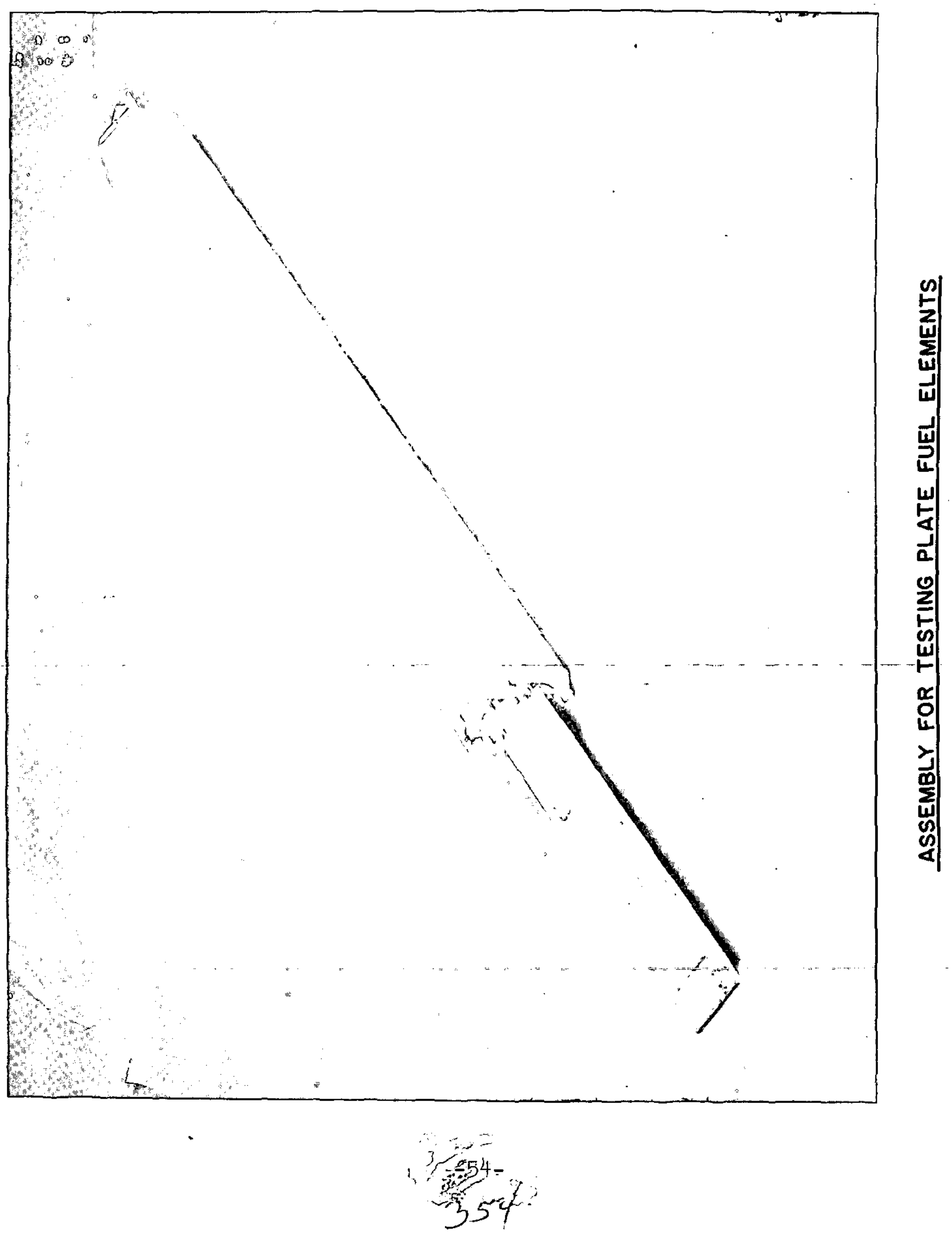


FIGURE 32

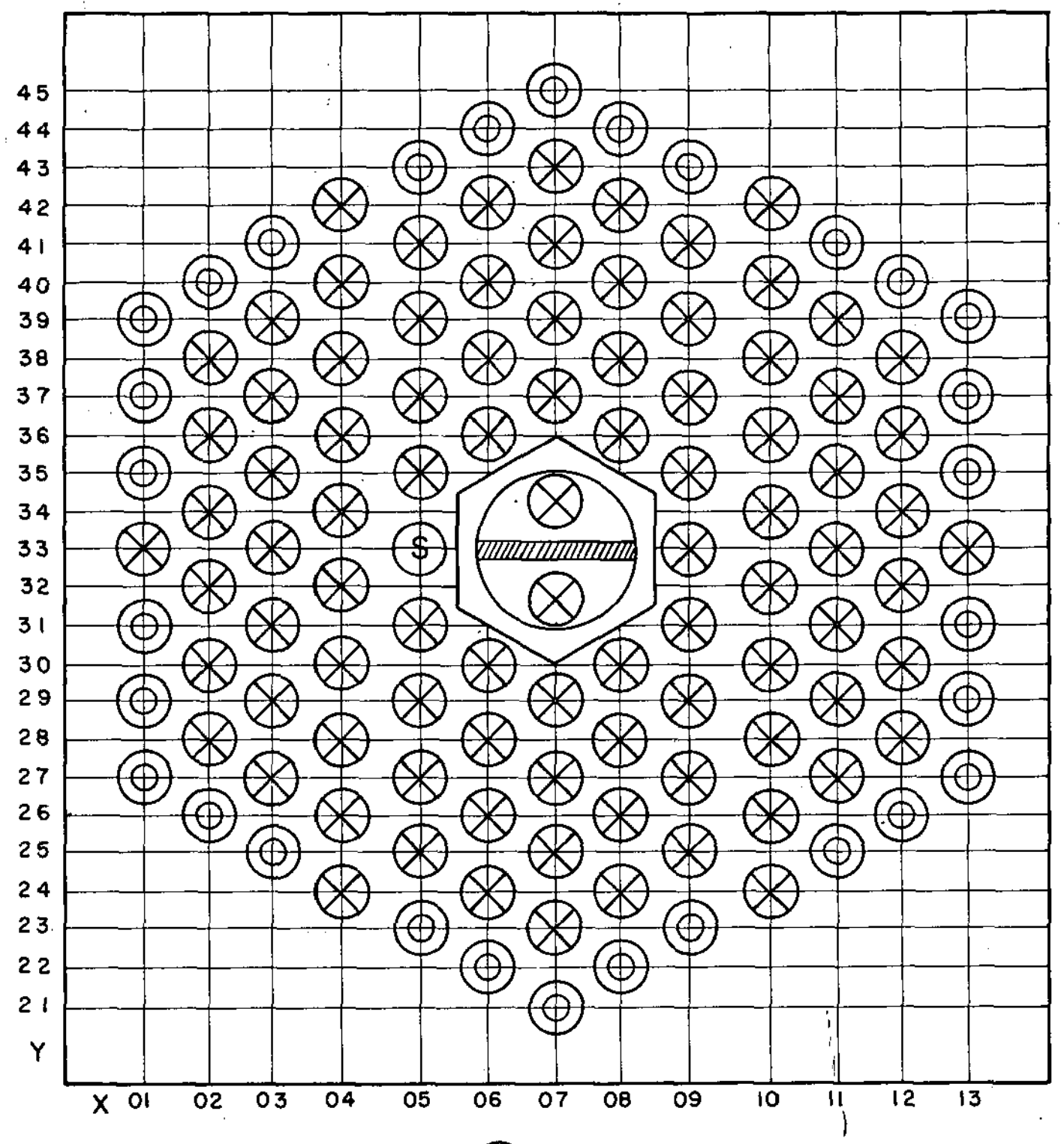

$\otimes$ fuel

(a) plastic

(S) Source

LATTICE CONFIGURATION FOR TESTING PLATE FUEL ELEMENTS 
FIGURE 33

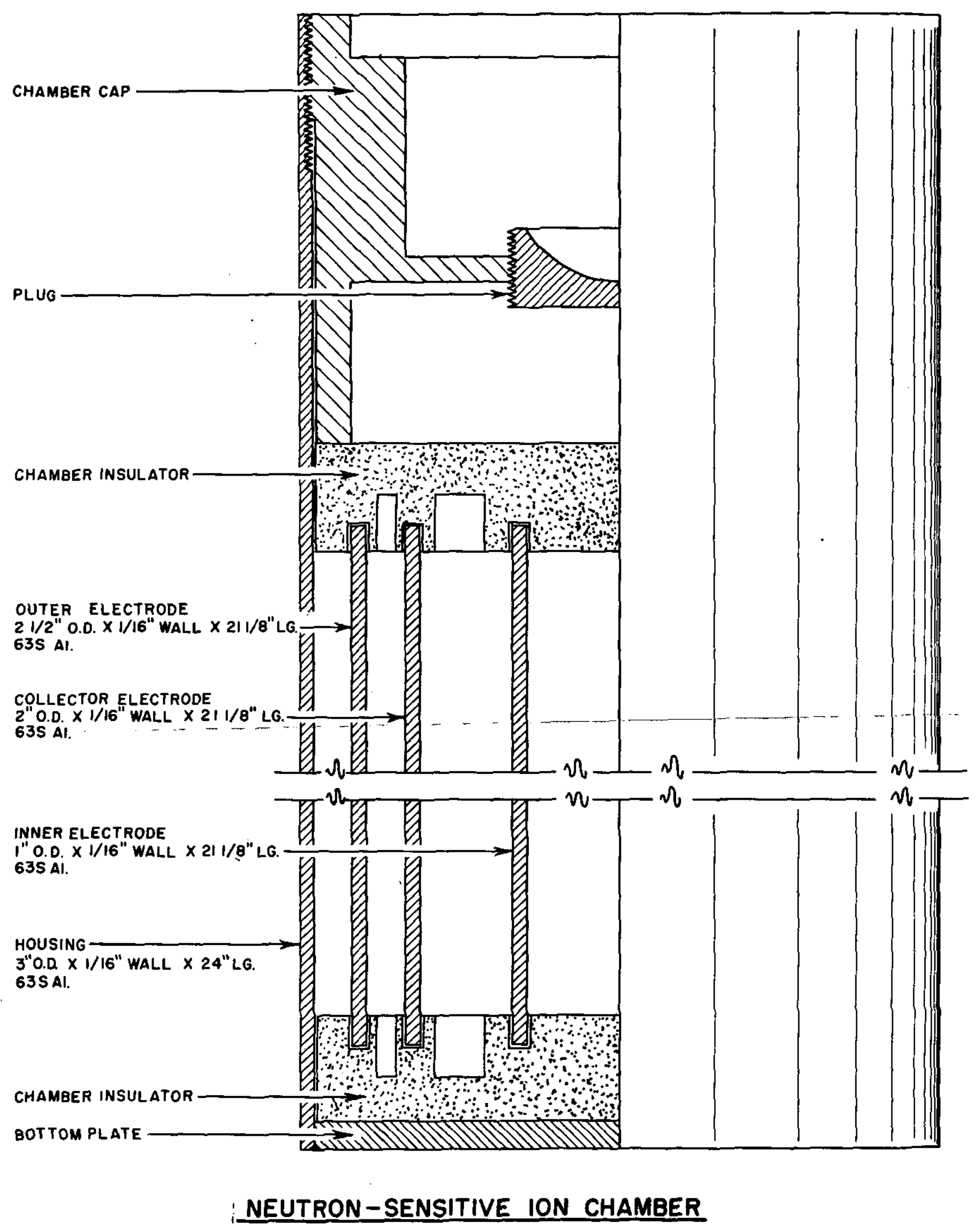




\section{FIGURE 34}

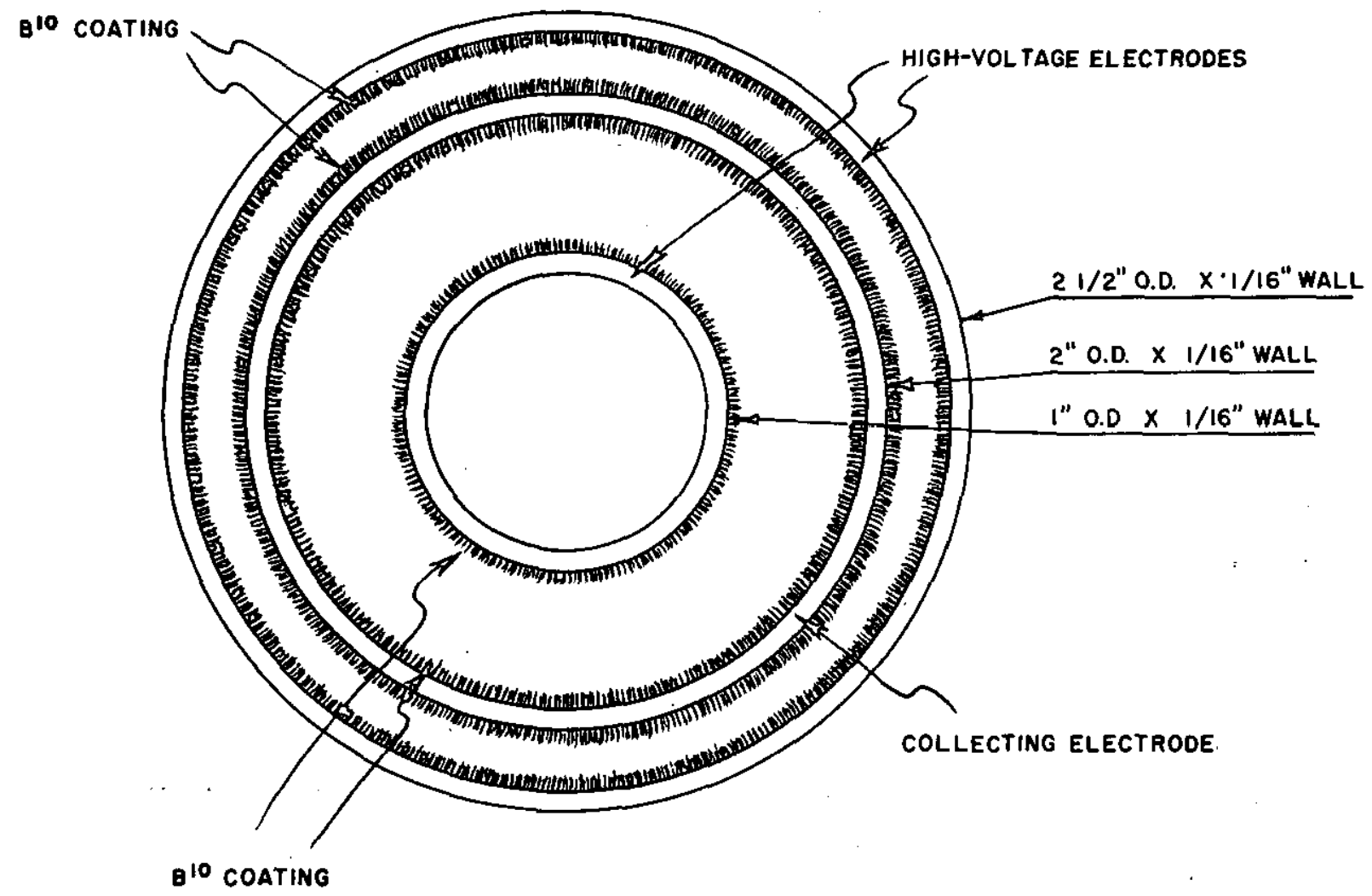

CROSS SECTION OF ION CHAMBER 


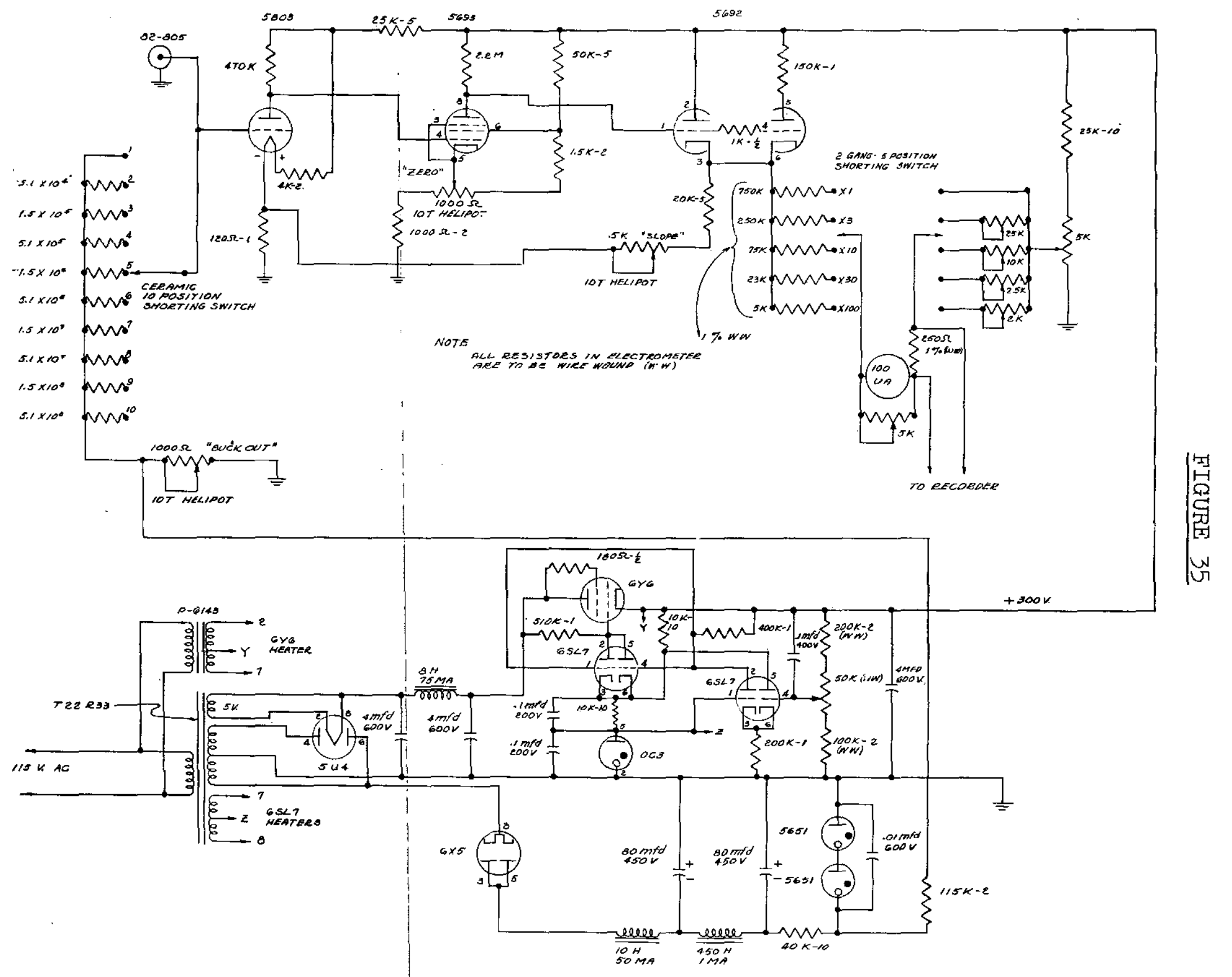

SCHEMATIC DIAGRAM OF THE DIFFERENTIAL ELECTROMETER 

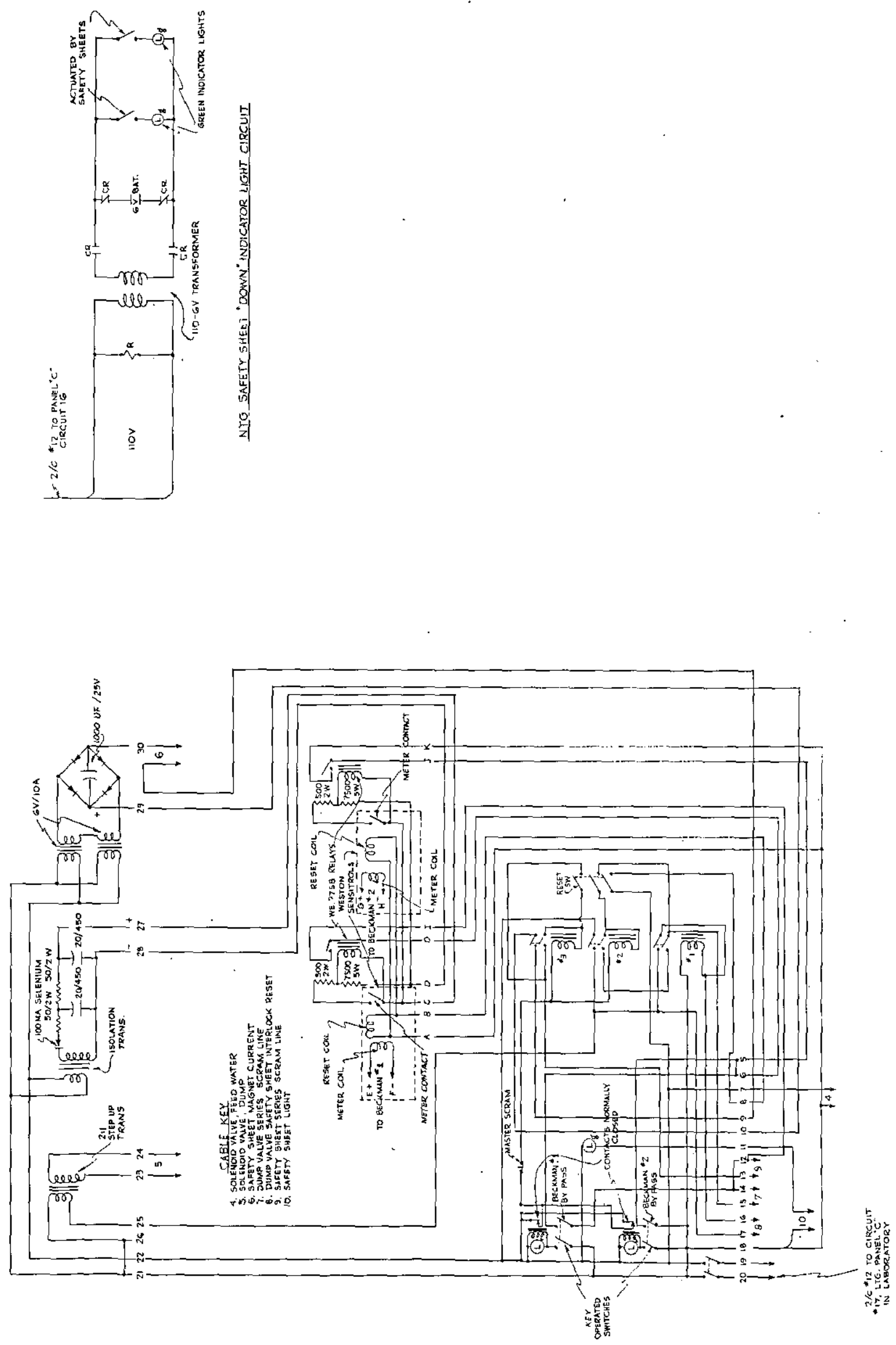

妾 